\title{
Captive Aerosol Growth and Evolution (CAGE) chamber system to investigate particle growth due to secondary aerosol formation
}

\author{
Candice L. Sirmollo ${ }^{1,2}$, Don R. Collins ${ }^{1,2}$, Jordan M. McCormick ${ }^{3}$, Cassandra F. Milan ${ }^{3}$, Matthew H. Erickson ${ }^{4}$, \\ James H. Flynn ${ }^{4}$, Rebecca J. Sheesley ${ }^{5}$, Sascha Usenko ${ }^{5}$, Henry W. Wallace ${ }^{6}$, Alexander A. T. Bui ${ }^{6}$, Robert J. Griffin ${ }^{6}$, \\ Matthew Tezak ${ }^{7}$, Sean M. Kinahan ${ }^{7,8}$, and Joshua L. Santarpia ${ }^{9}$ \\ ${ }^{1}$ Department of Chemical and Environmental Engineering, University of California Riverside, \\ Riverside, California 92521, USA \\ ${ }^{2}$ College of Engineering, Center for Environmental Research and Technology (CE-CERT), \\ University of California Riverside, Riverside, California 92507, USA \\ ${ }^{3}$ Department of Atmospheric Sciences, Texas A\&M University, College Station, Texas 77843, USA \\ ${ }^{4}$ Department of Earth and Atmospheric Sciences, University of Houston, Houston, Texas 77204, USA \\ ${ }^{5}$ Department of Environmental Science, Baylor University, Waco, Texas 76798, USA \\ ${ }^{6}$ Department of Civil and Environmental Engineering, Rice University, Houston, Texas 77005, USA \\ ${ }^{7}$ Sandia National Laboratory, Albuquerque, New Mexico 87123, USA \\ ${ }^{8}$ Biodefense and Health Security, University of Nebraska Medical Center, Omaha, Nebraska 68198, USA \\ ${ }^{9}$ Department of Pathology and Microbiology, University of Nebraska Medical Center, Omaha, Nebraska 68198, USA
}

Correspondence: Don R. Collins (donc@ucr.edu)

Received: 6 November 2020 - Discussion started: 3 December 2020

Revised: 19 March 2021 - Accepted: 20 March 2021 - Published: 6 May 2021

\begin{abstract}
Environmental chambers are a commonly used tool for studying the production and processing of aerosols in the atmosphere. Most are located indoors and most are filled with air having prescribed concentrations of a small number of reactive gas species. Here we describe portable chambers that are used outdoors and filled with mostly ambient air. Each all-Teflon ${ }^{\circledR} 1 \mathrm{~m}^{3}$ Captive Aerosol Growth and Evolution (CAGE) chamber has a cylindrical shape that rotates along its horizontal axis. A gas-permeable membrane allows exchange of gas-phase species between the chamber and surrounding ambient air with an exchange time constant of approximately $0.5 \mathrm{~h}$. The membrane is non-permeable to particles, and those that are injected into or nucleate in the chamber are exposed to the ambient-mirroring environment until being sampled or lost to the walls. The chamber and surrounding enclosure are made of materials that are highly transmitting across the solar ultraviolet and visible wavelength spectrum. Steps taken in the design and operation of the chambers to maximize particle lifetime resulted in averages of $6.0,8.2$, and $3.9 \mathrm{~h}$ for $\sim 0.06, \sim 0.3$, and $\sim 2.5 \mu \mathrm{m}$ diameter particles, respectively. Two of the newly developed
\end{abstract}

CAGE chamber systems were characterized using data acquired during a 2-month field study in 2016 in a forested area north of Houston, TX, USA. Estimations of measured and unmeasured gas-phase species and of secondary aerosol production in the chambers were made using a zero-dimensional model that treats chemical reactions in the chamber and the continuous exchange of gases with the surrounding air. Concentrations of $\mathrm{NO}, \mathrm{NO}_{2}, \mathrm{NO}_{y}, \mathrm{O}_{3}$, and several organic compounds measured in the chamber were found to be in close agreement with those calculated from the model, with all having near 1.0 best fit slopes and high $r^{2}$ values. The growth rates of particles in the chambers were quantified by tracking the narrow modes that resulted from injection of monodisperse particles and from occasional new particle formation bursts. Size distributions in the two chambers were measured intermittently $24 \mathrm{~h} \mathrm{~d}^{-1}$. A bimodal diel particle growth rate pattern was observed, with maxima of about $6 \mathrm{~nm} \mathrm{~h}^{-1}$ in the late morning and early evening and minima of less than $1 \mathrm{~nm} \mathrm{~h}^{-1}$ shortly before sunrise and sunset. A pattern change was observed for hourly averaged growth rates between late summer and early fall. 


\section{Introduction}

Atmospheric aerosols play a role in atmospheric chemistry, health, and climate forcing. Secondary aerosol is produced in the atmosphere from the oxidation of precursor gas-phase species and can either add to existing particles or nucleate to form new ones, which is the initial step in the process known as new particle formation (NPF). Condensation, gasparticle partitioning, and heterogeneous reactions are known mechanisms by which secondary aerosol contributes to particle growth. Several groups have developed particle growth models that are constrained by measurements and that represent some or all of these growth mechanisms (Stolzenburg et al., 2005; Yli-Juuti et al., 2013; Tröstl et al., 2016). Atmospheric aerosol formation and growth is regionally and globally significant and thus these modeled mechanisms should be included in larger-scale models that investigate the climate effects of aerosols (Kulmala and Kerminen, 2008). Though aerosol formation, growth, and atmospheric processing have been the focus of many studies, further investigations are required to realistically represent aerosol behavior (Kroll and Seinfeld, 2008; Hallquist et al., 2009; Laj et al., 2009).

Laboratory reactors such as environmental chambers and oxidation flow reactors are tools that are commonly used to better understand and predict atmospheric processes under controlled settings. Environmental chambers have been used in the laboratory and the field to study gas-phase kinetics, urban air pollution, particle formation and growth, and aqueous secondary organic aerosol (SOA) production. They have been used to investigate secondary aerosol formation from vehicle exhaust (Weitkamp et al., 2007; Vu et al., 2019), physical, chemical, and optical properties of aging biomass burning particles (Hennigan et al., 2011; Zhong and Jang, 2014; Tkacik et al., 2017; Smith et al., 2019), and the impact of atmospheric conditions on the viability of bacteria (Brotto et al., 2015; Massabò et al., 2018). They provide a method to simulate the aerosol production that would occur in a parcel of air in the atmosphere. Interpretations of gas-particle interactions in chamber systems can guide development of models and model parameterizations used to describe real-world atmospheric processing of particles.

Environmental chambers vary in design in their volume, materials, light source, and temperature range, and in performance and applicability in their timescale of experiments, particle lifetime, and wall losses. Typically, Teflon ${ }^{\circledR}$ materials such as fluorinated ethylene polypropylene (FEP) are used for the chamber walls due to their inert and ultraviolet (UV) transmission properties. However, environmental chambers have also been constructed of stainless steel (De Haan et al., 1999; Glowacki et al., 2007; Duplissy et al., 2010; Wang et al., 2011; Massabò et al., 2018), aluminum (Saathoff et al., 2003), quartz (Barnes et al., 1994), and Pyrex glass (Doussin et al., 1997). Some chambers are designed to be operated indoors (Doussin et al., 1997; Cocker et al., 2001; Saathoff et al., 2003; Carter et al., 2005; Paulsen et al.,
2005; Presto et al., 2005; King et al., 2009; Wang et al., 2011; Hu et al., 2014; Wang et al., 2014); others are developed to be used outdoors (Jeffries et al., 1976; Becker, 1996; Klotz et al., 1998; Lee et al., 2004; Rohrer et al., 2005; Chung et al., 2008; Im et al., 2014; Ren et al., 2017). A few chamber systems have been designed to be portable (Shibuya et al., 1981; Hennigan et al., 2011; Bonn et al., 2013; Platt et al., 2013; Kaltsonoudis et al., 2019; Vu et al., 2019). Several comprehensive reviews of existing environmental chambers have been published (Becker, 2006; Lee et al., 2009; Seakins, 2010; Hidy, 2019).

In this paper, the development and characterization of the Captive Aerosol Growth and Evolution (CAGE) chamber system will be discussed. The CAGE chambers are portable and designed to be used in the field. Observed changes in aerosols that are generated and injected into the chambers provide useful information about atmospheric processing and the rates and mechanisms of particle growth. Experience with a previous generation of this chamber system informed the design of that described here. That previous version, also referred to as the quasi-atmospheric aerosol evolution study (QUALITY) chamber, consisted of a portable $1.2 \mathrm{~m}^{3} \mathrm{UV}-$ transmitting upper reaction chamber with a sheet of gaspermeable membrane across the bottom that allowed ambient gas-phase species to enter the reaction chamber where seed particles were injected. A photo is shown in Fig. S1 in the Supplement. They were used to study the aging of primary particles, such as of black carbon in the polluted urban areas of Houston, TX, USA, and Beijing, China (Glen, 2010; Peng et al., 2016, 2017). The design of the version described here differs considerably from the first generation and is therefore discussed in detail.

\section{Design of CAGE chamber system}

\subsection{CAGE chambers}

A sketch and photo of one of the two identical CAGE chambers that were constructed are shown in Fig. 1. The core of each chamber is a $1 \mathrm{~m}^{3}$ all-Teflon ${ }^{\circledR}$ cylindrical reactor constructed primarily of UV-transmitting 2 mil $(0.05 \mathrm{~mm})$ thick FEP film (a in Fig. 1). The only non-FEP section is the $\sim 0.2$ mil $(0.005 \mathrm{~mm})$ gas-permeable expanded polytetrafluoroethylene (ePTFE; Phillips Scientific) membrane sheet (b), located at the back end of the cylinder as shown in both the sketch and photo. The stainless steel internal support structure of the chamber is fully wrapped with highly reflective high-density PTFE thread tape that was first baked at about $120^{\circ} \mathrm{C}$ overnight to eliminate any residual volatile species. Each chamber is suspended in a stainless steel rectangular enclosure that was powder coated with a reflective white fluoroethylene vinyl ether (FEVE) fluoropolymer paint. The rectangular enclosure is covered by $4.8 \mathrm{~mm}$ thick UV-transmitting Plexiglas G-UVT acrylic sides (c) in order 
to block wind that would otherwise increase mixing and, consequently, particle loss rate. FEP sheets cover all interior surfaces of the enclosure within about $0.5 \mathrm{~m}$ of the far (right) gas-permeable end, as shown in the sketch and photo. The FEP walls of the chamber bag are pulled tight across internal rings so that a solid cylindrical shape can be maintained throughout the experiments, minimizing turbulent mixing inside and the increased particle loss that would result.

\subsection{Ambient light source}

Whereas most environmental chambers are illuminated by UV-emitting black lights, these utilize solar radiation for their light source. The overall light transmittance through the chamber and acrylic sheets is evident in the closeup photo in Fig. S2 in the Supplement. The small loss of UV (and visible) solar radiation through the acrylic and FEP is partially offset by reflection off a highly UV-reflective $3.2 \mathrm{~mm}$ thick PTFE gasket sheet (Inertech SQ-S) just below the chamber (d). At the site at which the field study described below was conducted, both chambers were oriented on the south side of an instrumented trailer and with their ePTFE membranes facing north to minimize shading throughout the day. Prior to that study, an Ocean Insight Flame spectrometer was used to measure cosine-weighted solar spectral intensity outside and at a point between the bottom of one of the chambers and the reflective PTFE gasket (point e in Fig. 1). The results shown in Fig. 2 represent the sum of the upwelling and downwelling measurements (spectroradiometer receptor pointing straight down and up, respectively). The broad spectral transmittance of the chamber and enclosure sides and the broad spectral reflectance of the PTFE gasket result in the close chamber and outside match over the full UV range. Because the spectroradiometer receptor could not be positioned inside the chamber, the offset between the two curves is only an approximate indicator of the absolute agreement between the intensities inside and outside of the chamber.

\subsection{Rotating chamber}

The cylindrical reaction chamber is supported at both ends by mounted bearings that are attached to the enclosure frame. A DC-powered motor connected to the chamber through a chain and pair of sprockets rotates it along its horizontal axis at approximately 1 revolution per minute (rpm). The slow rotation minimizes loss of large particles due to gravitational settling and losses of all sizes of particles by minimizing temperature gradients and dampening convective eddies. The technique of using a rotating chamber, or drum, to suspend sub-10 $\mu \mathrm{m}$ biological particles for extended periods of time is commonly employed in the field of aerobiology (Asgharian and Moss, 1992; Santarpia et al., 2020). The optimum rotation rate for particles smaller than $10 \mu \mathrm{m}$ has been shown to be around 1-2 rpm (Goldberg et al., 1958; Goldberg, 1971; Krumins et al., 2008), though experimental studies suggest higher rotation rates may be preferable (Sutton, 2005). Stainless steel tubes with a $0.95 \mathrm{~cm}$ outer diameter that are used as aerosol injection and sampling ports extend out from the center axle on both ends of the chamber and are sealed using radial O-rings. Those tubes terminate $0.4 \mathrm{~m}$ inside both ends of the chamber at a radial distance of $8 \mathrm{~cm}$ out from the center of the axle.

\subsection{Exchange of ambient air into the reaction chamber}

Several $\mathrm{m}^{3} \mathrm{~min}^{-1}$ of ambient air is drawn through an FEPlined inlet on top of the chamber ( $f$ in the photo in Fig. 1) that is protected by an FEP-wrapped rain cover. The ambient air circulates behind the gas-permeable ePTFE membrane and then around the chamber to the opposite end of the enclosure where it is exhausted through a port ( $\mathrm{g}$ in the photo in Fig. 1) connected to a blower (h; Allegro 9533) that is located below the acrylic frame. The ventilation air flow created by the blower, together with the use of light reflective materials and coatings, helps minimize heating of the chamber above the surrounding temperature during daytime. The FEP sheets covering the internal surfaces on the inlet end of the enclosure minimize contact of the air with any non-Teflon ${ }^{\circledR}$ surface prior to reaching the $0.9 \mathrm{~m}^{2}$ ePTFE membrane. As is described in Sect. 4, an effective exchange flow rate across the ePTFE membrane is estimated to be $33 \mathrm{~L} \mathrm{~min}^{-1}$. The driving force of gas exchange across the membrane and into the chamber is the difference in concentrations of gas-phase species between the chamber air and the ambient air that is flushed through the enclosure. Efficient gas exchange across the membrane maintains near-ambient trace gas concentrations in the chamber without diluting the captive aerosol, as would occur if ambient air were instead continuously pumped into the chamber, as is further discussed in Sect. 5. The membrane is similar to material commonly used in filters used to collect aerosol samples and minimizes infiltration of ambient particles into the chamber, where they would mix with the narrow size mode populations of particles that are tracked over time.

\subsection{Experimental procedure: instrumentation}

Similar to the dual-chamber systems described by Tkacik et al. (2017) and Kaltsonoudis et al. (2019), two identical chambers (called A and B) were utilized to evaluate the influence of differing conditions on the behavior of captive particles. For the experiments described here, unperturbed ambient air was circulated behind each of the permeable membranes and the contrast in conditions was achieved by covering Chamber B with a light shield that reduced daytime UV intensity to below $1 \%$ of that in Chamber A. With the exception of the results from the chamber-ambient characterization experiment described below, only measurements from Chamber A will be described here. 

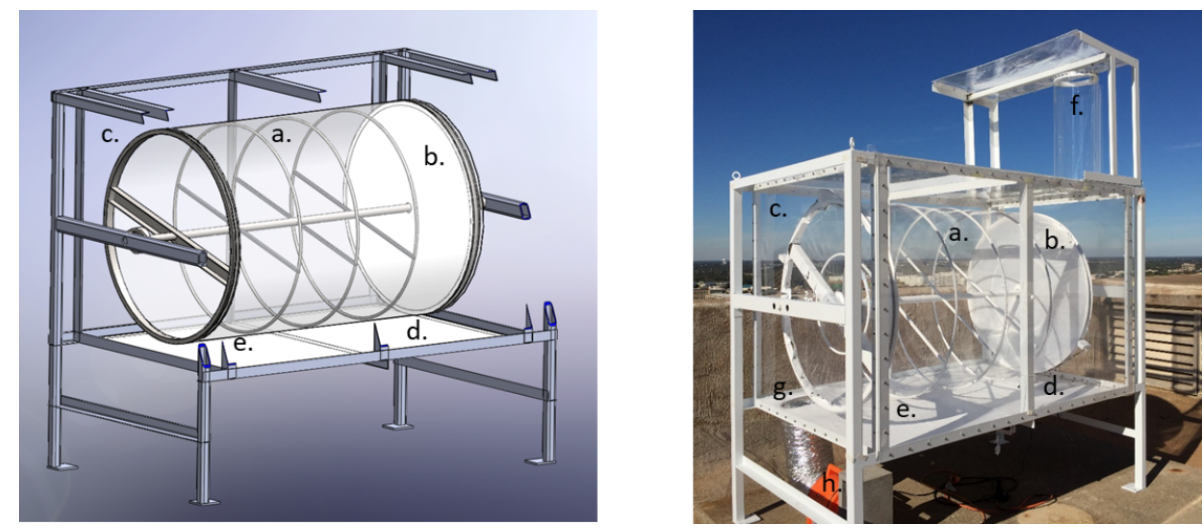

Figure 1. Sketch and photo of a CAGE chamber.

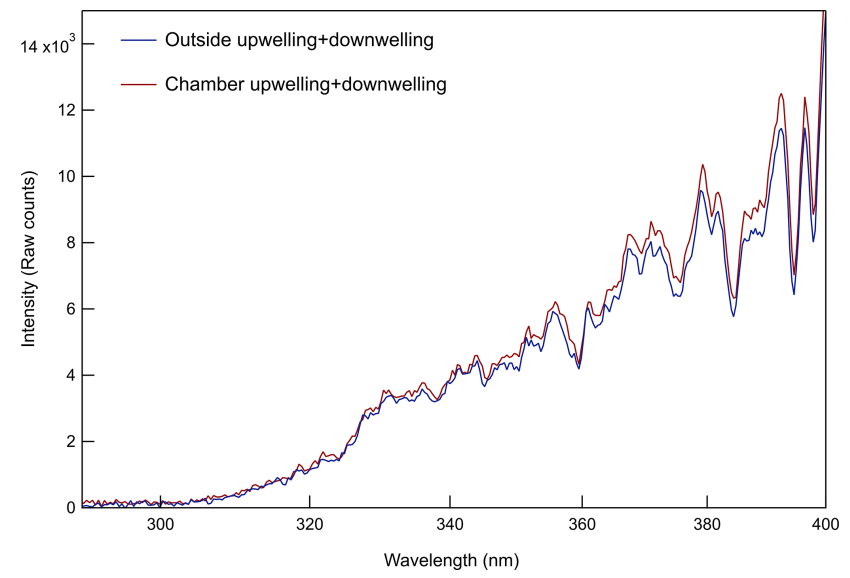

Figure 2. Comparison of spectral intensity measured just below one of the chambers (around point e in Fig. 1) and just outside of the chamber enclosure on a sunny day.

Monodisperse seed particles were generated by atomizing an ammonium sulfate solution with a TSI 3076 atomizer, drying with a silica gel diffusion dryer, and separating a narrow size range with a differential mobility analyzer (DMA). The monodisperse particle mode was then injected into one of the chambers at a time, as discussed in Sect. 5. The instrumentation was configured to sample from both the inside of each of the two chambers and ambient air, with a repeated sampling sequence of Chamber $\mathrm{A} \rightarrow$ Chamber B $\rightarrow 4 \times$ ambient, such that sample was extracted from each chamber only $1 / 6$ th of the time in order to minimize the loss rate of the captive particles. Particle size distributions spanning the diameter range from 0.013 to $0.60 \mu \mathrm{m}$ were measured using a custom-built scanning mobility particle sizer (SMPS) equipped with a TSI 3762 condensation particle counter (CPC) and a high flow DMA (Stolzenburg et al., 1998). The sampled aerosol was dried with a Nafion tube bundle and charge neutralized with a soft x-ray neutralizer prior to entering the DMA. A TSI UV-aerodynamic parti- cle sizer (APS; 3314) was used in parallel with the SMPS to measure the aerodynamic size distributions of supermicron bioaerosol particles that were intermittently injected into the chambers.

Throughout roughly the first half of the study described here, the Mobile Air Quality Lab (MAQL) developed and operated by researchers from the University of Houston, Baylor University, and Rice University was located adjacent to the CAGE chambers at the field site. Instrumentation inside the MAQL measured trace gas concentrations and aerosol composition (Leong et al., 2017; Wallace et al., 2018). Ozone $\left(\mathrm{O}_{3}\right)$ was measured with a Thermo Environmental 49C analyzer. Nitric oxide (NO), nitrogen dioxide $\left(\mathrm{NO}_{2}\right)$, and the sum of nitrogen oxides $\left(\mathrm{NO}_{y}\right)$ were measured with an Air Quality Design, Inc. (AQD), high sensitivity chemiluminescence $\mathrm{NO}$ detector. $\mathrm{NO}_{y}$ was measured by conversion to $\mathrm{NO}$ using a molybdenum oxide catalytic converter maintained at $320^{\circ} \mathrm{C}$. $\mathrm{NO}_{2}$ was measured by photolytic conversion of $\mathrm{NO}_{2}$ to $\mathrm{NO}$ using an $\mathrm{AQD}$ blue light converter. An Ionicon Q300 quadrupole proton transfer reaction mass spectrometer (PTR-MS) measured concentrations of a fixed set of VOCs. Of the 19 VOCs measured, analysis here focused on the subset of species that were at least sometimes present at concentrations above their detection limit and were not significantly impacted by interference from other species detected at the same masses. The species analyzed include acetaldehyde (detected mass $=45 \mathrm{Da}$ ), acetone (59), isoprene (69), methyl vinyl ketone+methacrolein (MVK + MACR; 71), methyl ethyl ketone (MEK; 73), benzene (79), toluene (93), and monoterpenes (137). A $2: 1 \alpha$ pinene: $\beta$-pinene split in ambient air was assumed for the monoterpenes, partly based on regional emissions estimates with the Model of Emissions of Gases and Aerosols from Nature (MEGAN) (Guenther et al., 2012). Because the chamber inlet and outlet were not configured to allow simultaneous sampling of particles and trace gases, the gas analyzers sampled from the chambers only during a $3 \mathrm{~d}$ period described below. Non-refractory submicron aerosol composi- 


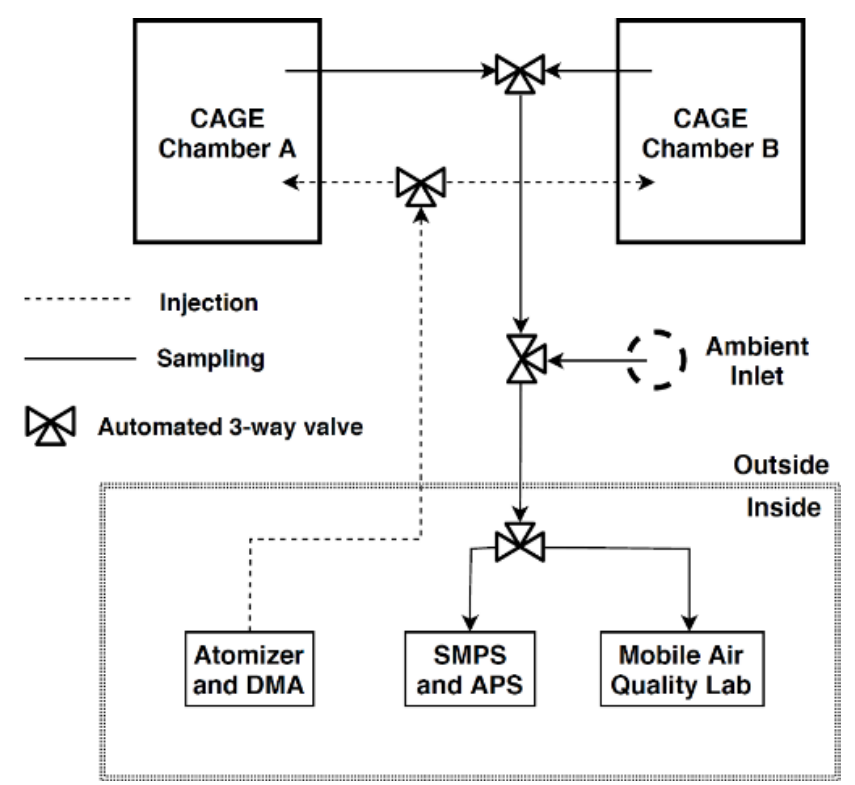

Figure 3. Placement and orientation of the CAGE chambers relative to the instrument trailer, and the tubing and valve configuration used to inject particles into and sample particles from both CAGE chambers.

tion and mass concentration were measured with an Aerodyne high-resolution time-of-flight aerosol mass spectrometer (HR-ToF-AMS). Unlike the gas-phase instruments, the AMS intermittently sampled air from the chambers throughout the month the MAQL was operated at the field site. The approximate placement of the CAGE chambers and the valve and tubing configuration used to alternate between Chamber $\mathrm{A}$ and Chamber B for aerosol injection and sampling is depicted in Fig. 3. LabVIEW software was used to automate control of injection and sampling systems, as well as to monitor parameters throughout the system.

\section{Field site description}

The chambers were evaluated during a field study at the WG Jones State Forest (JSF) from 15 August 2016 to 14 October 2016 . The JSF site is a roughly 2000 -acre $\left(8 \mathrm{~km}^{2}\right)$ pinedominated forest located between Conroe and The Woodlands in southeast Texas, USA. The clearing in which the chambers were located, its location within the nearly rectangular state forest, and its proximity to the Houston area are shown in the set of satellite images in Fig. 4. A photo of the MAQL instrumentation, CAGE chambers, and research trailers at the JSF sampling site is shown in Fig. S3 in the Supplement.

The wind rose shown in Fig. S4 in the Supplement was calculated from the winds observed at the nearby Conroe, TX, airport during the field study period. Those data highlight the prevalence of southeasterly winds, which bring the complex and concentrated mixture of pollutants from Houston into an area with high emissions of highly reactive biogenic hydrocarbons such as isoprene and monoterpenes. The goal of the field study was to investigate how fast and why particles grew in an environment that is impacted by high emissions rates of both anthropogenic and biogenic gases.

\section{Relationship between ambient and chamber gas-phase composition}

The measurements of trace gas concentrations made by instrumentation in the MAQL allowed the relationship between chamber and ambient air to be characterized by temporarily reconfiguring the mobile laboratory inlet to alternate between sampling from the chambers and from outside. These chamber-ambient characterization experiments were conducted over a $3 \mathrm{~d}$ break from the routine particle growth measurements from midday 9 September 2016 to midday 12 September 2016. During these experiments, automated valves were controlled to produce the repeated sampling loop: Ambient $(15 \mathrm{~min}) \rightarrow$ Chamber A $(15 \mathrm{~min}) \rightarrow$ Ambient $(15 \mathrm{~min}) \rightarrow$ Chamber B $(15 \mathrm{~min})$. Unlike the rest of the 2-month study, Chamber B was uncovered for these experiments in order to assess the chamber-to-chamber consistency. Similar to what has been observed during prior chamber-ambient comparisons, measured trace gas concentrations in each chamber could be explained by treating the volume as a continuous stirred-tank reactor (CSTR). The resulting rate of change of the concentration of any of the trace gases can then be expressed as

$\frac{\mathrm{d} C_{\mathrm{ch}}}{\mathrm{d} t}=P-L+\frac{Q_{\mathrm{ex}}}{V_{\mathrm{ch}}} C_{\mathrm{amb}}-\frac{Q_{\mathrm{ex}}}{V_{\mathrm{ch}}} C_{\mathrm{ch}}$,

where $C_{\mathrm{ch}}$ is the concentration in the chamber, $C_{\mathrm{amb}}$ is the ambient concentration, $V_{\mathrm{ch}}$ is the volume of the chamber $(\approx 1000 \mathrm{~L}), P$ and $L$ are the per unit volume rates of chemical production and loss in the chamber, respectively, and $Q_{\mathrm{ex}}$ is an effective exchange flow rate across the ePTFE membrane. The $Q_{\text {ex }}$ cannot be measured directly and is instead estimated using Eq. (1) and the time series of concentrations measured in the chamber and outside. It is best determined for a gas that has negligible chemical production and loss $(P=L=0)$ and that is present at concentrations well above the instrument detection limit. $\mathrm{NO}_{y}$ best satisfied those requirements among the species measured during the characterization experiments. The value of $Q_{\text {ex }}$ was estimated as that resulting in the maximum correlation $\left(r^{2}\right)$ between the time series of the concentration measured in the chambers and that calculated from the ambient time series using Eq. (1). A $Q_{\mathrm{ex}}$ of $33 \mathrm{~L} \mathrm{~min}^{-1}$ resulted in a peak $r^{2}$ of about 0.97 for both chambers (Fig. S5 in the Supplement). The resulting $3 \mathrm{~d}$ time series for $\mathrm{NO}_{y}$ in Fig. 5 shows that the mixing ratios in the chambers closely match those calculated from the ambient measurements. Treating the chamber 

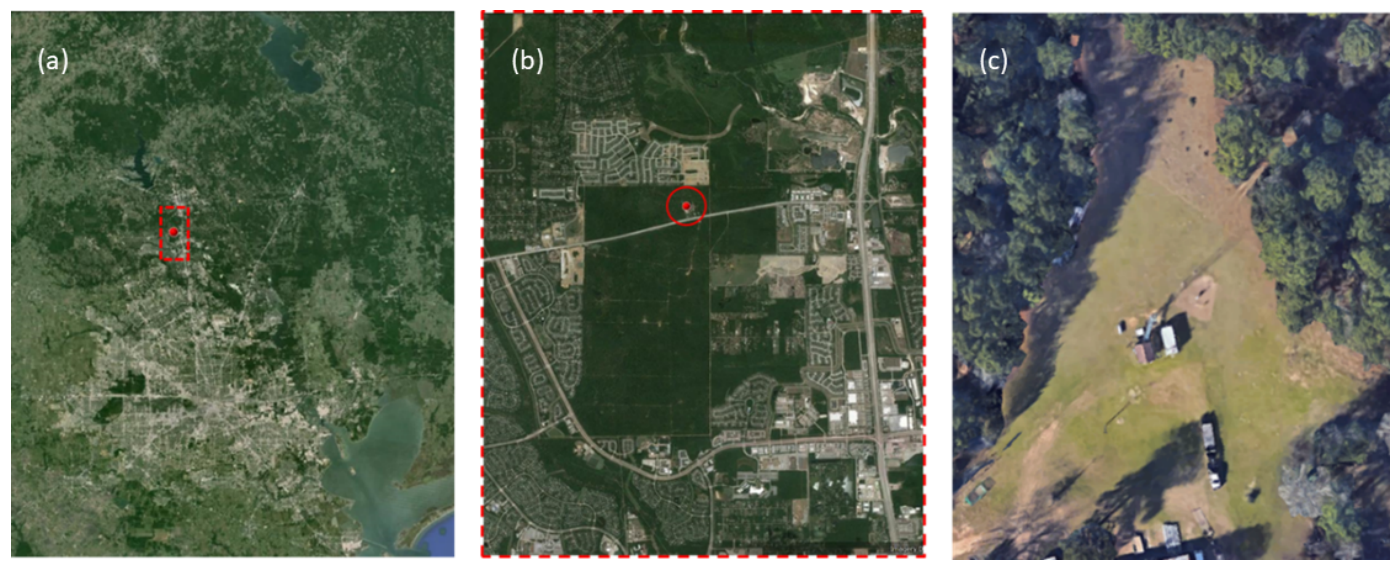

Figure 4. Satellite images of the WG Jones State Forest (JSF) site at which the field study was conducted. The location of JSF relative to Houston is shown in (a), the location of the field site within the nearly rectangular JSF in (b), and the clearing at which the chambers and instrument trailers were located in (c). Map data (C Google Earth 2017.

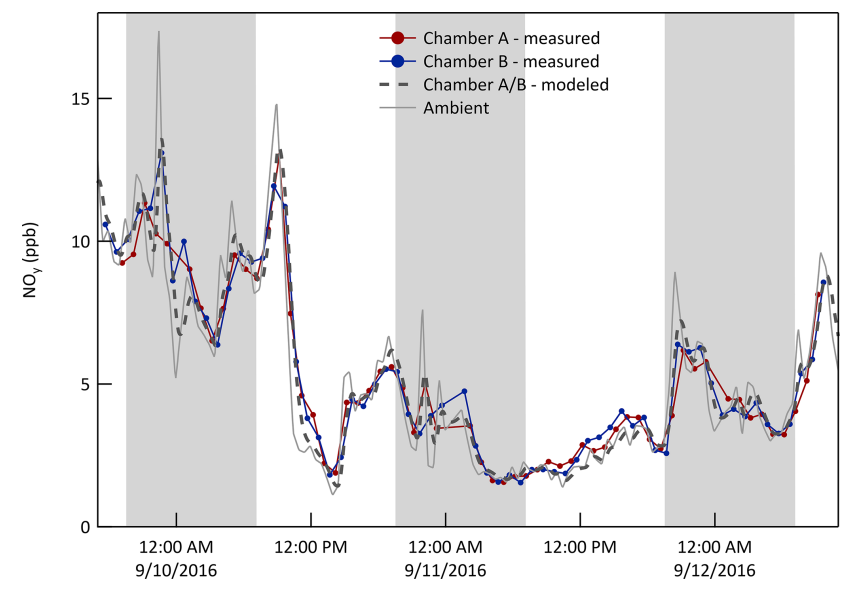

Figure 5. Time series of $\mathrm{NO}_{y}$ mixing ratio (ppb) measured in both chambers, measured just outside of them, and calculated from the ambient time series by modeling them as CSTRs with an exchange flow rate, $Q_{\mathrm{ex}}$, of $33 \mathrm{~L} \mathrm{~min}^{-1}$. The shaded bands represent nighttime.

as a CSTR captures the observed smoothing of short duration peaks and troughs in the ambient data. Figure 6 presents the same data for $\mathrm{NO}_{y}$ (and other species as discussed below) as pairs of mixing ratios (i) measured in the chambers $(y$-axis) and (ii) calculated from the ambient measurements ( $x$-axis). The best fit lines through the $\mathrm{NO}_{y}$ pairs have slopes of 0.98 and 1.00 for Chambers A and B, respectively. For all other measured species (or groups of species), chemical loss and/or production over the approximate $V_{\mathrm{ch}} / Q_{\mathrm{ex}}=30 \mathrm{~min}$ residence in the chambers may be significant. For free radicals and other highly reactive or condensable species with typical atmospheric lifetimes much shorter than 30 min (e.g., hydroxyl radical, $\mathrm{OH} \cdot$, and nitrate radical, $\mathrm{NO}_{3} \bullet$ ), exchange across the ePTFE membrane is insignificant and $P \approx L$ in Eq. (1).
A simple CSTR zero-dimensional (OD) model was developed to interpret the results from the chamber-ambient characterization experiment and to subsequently use ambient measurements made throughout the period when the MAQL was at the site to estimate concentrations of measured and unmeasured species in the chambers. The model numerically integrates the time-dependent changes resulting from the $33 \mathrm{~L} \mathrm{~min}^{-1}$ gas exchange and the reactions listed in Table $\mathrm{S} 1$ in the Supplement. Only those reactions expected to have significant influence on the concentrations of measured or otherwise important species were included. Most photolysis rate constants were calculated from measured spectral intensity. The only exception is that for $\mathrm{NO}_{2}$ during daytime, which was instead calculated assuming ambient $\mathrm{NO}, \mathrm{NO}_{2}$, and $\mathrm{O}_{3}$ concentrations satisfied the photostationary state relationship, $J_{\mathrm{NO}_{2}}=k\left[\mathrm{O}_{3}\right][\mathrm{NO}] /\left[\mathrm{NO}_{2}\right]$, where [ ] indicates concentration. Some reactions are intentionally not balanced where one or more of the products are not tracked in the model (e.g., $\mathrm{NO}_{3} \cdot+\mathrm{RO}_{2} \cdot \rightarrow \mathrm{NO}_{2}$ ) and some reactions combine a series of steps wherein only the step controlling the overall rate is included (e.g., $\mathrm{NO}_{2}+h v \rightarrow \mathrm{NO}+\mathrm{O}_{3}$ ). The OD model was used to calculate concentrations of measured (e.g., $\mathrm{O}_{3}$ and isoprene) and unmeasured (e.g., $\mathrm{OH} \cdot$ and $\mathrm{NO}_{3}{ }^{\circ}$ ) gases and to estimate secondary aerosol production rates resulting from reactions of $\mathrm{SO}_{2}$ with $\mathrm{OH} \cdot$ and reactions of hydrocarbons with $\mathrm{OH} \cdot, \mathrm{NO}_{3} \cdot$, and $\mathrm{O}_{3}$. The concentrations measured in the chambers for almost all species agree well with those calculated from the ambient measurements, as is reflected in the near 1.0 best fit slopes and high $r^{2}$ values shown in Fig. 6. There is more scatter about the $1: 1$ line for the monoterpenes than for other species, which is largely the result of noise in the measurements, as the mixing ratios were close to the detection limit for most of the measurement period. Uncertainty in the relative abundance of the different monoterpene species may also contribute to this noise because reaction rates vary considerably among the 
species, while only the sum was measured by the PTR-MS. Measured concentrations of MEK were generally higher than predicted, which is believed to be the result of production in the chamber from oxidation of species such as butane that were not measured and therefore not included in the model. Described below are measured and modeled concentration time series for the $\mathrm{NO} / \mathrm{NO}_{2} / \mathrm{O}_{3}$, isoprene $/ \mathrm{MVK}+\mathrm{MACR}$, and $\mathrm{O}_{3}$ /acetaldehyde systems that, collectively, elucidate the relationship between conditions in the chamber and those outside.

$\mathrm{NO} / \mathrm{NO}_{2} / \mathrm{O}_{3}$. Whereas the concentration of the sum of all nitrogen oxides $\left(\mathrm{NO}_{y}\right)$ is roughly conserved over the chamber-ambient exchange time, that of its more reactive components may not be. During the daytime, approximately steady state cycling between $\mathrm{NO}, \mathrm{NO}_{2}$, and $\mathrm{O}_{3}$ minimizes any differences between chamber and ambient concentrations. At night, however, reaction of $\mathrm{O}_{3}$ with both $\mathrm{NO}$ and $\mathrm{NO}_{2}$ results in concentrations in the chamber that are, conceptually, what would be expected about $30 \mathrm{~min}$ (= $\left.V_{\mathrm{ch}} / Q_{\mathrm{ex}}\right)$ downwind of its physical location. The model captures the influence of the reactions, resulting in close agreement between the expected and measured mixing ratios for both $\mathrm{NO}$ and $\mathrm{NO}_{2}$, as is shown in the time series in Fig. 7 and in the clustering of points around the $1: 1$ lines in Fig. 6. For clarity, only the results for one of the two chambers (B) are shown in the time series, while the measurement and model pairs from both chambers are shown in Fig. 6.

Isoprene/MVK $+M A C R$. Oxidation of reactive hydrocarbons by $\mathrm{OH} \cdot, \mathrm{O}_{3}$, and $\mathrm{NO}_{3} \cdot$ creates a mixture of products that may subsequently react or may condense on the particles that were injected into or formed in the chamber. Biogenic VOCs including isoprene and monoterpenes were typically the most concentrated hydrocarbons at the forested site. Isoprene chemistry is most important during the daytime as its emission rate is largely controlled by solar intensity, whereas the temperature-dependent emission of monoterpenes varies comparatively little throughout the day or night. Figure 8 shows the influence of in-chamber chemistry on the mixing ratios of isoprene and its oxidation products MVK + MACR (only the sum of the two was measured with the PTR-MS). During the daytime and early evening when concentrations of $\mathrm{OH} \cdot$ and $\mathrm{O}_{3} / \mathrm{NO}_{3} \cdot$, respectively, are high, both the expected and measured mixing ratios of isoprene are lower and those of MVK + MACR are higher than those measured outside. For both species the CSTR OD model captures the features in the time series quite well with resulting average best fit slopes and $r^{2}$ of 0.95 and 0.97 for isoprene and 1.03 and 0.97 for MVK + MACR.

$\mathrm{O}_{3}$ /acetaldehyde. Reaction of $\mathrm{O}_{3}$ with the Teflon ${ }^{\circledR}$ walls and/or impurities on those walls results in a slightly lower concentration in the chamber than outside, as shown in Fig. 9a. To represent this in the model, an $\mathrm{O}_{3}+$ Wall reaction was included and its rate constant adjusted to match the observations in each chamber. Additionally, as reported elsewhere (de Gouw and Warneke, 2007), surface reaction of
$\mathrm{O}_{3}$ produces acetaldehyde, which is believed to be responsible for the higher concentrations in the chamber than outside evident in Fig. 9b. Thus, an acetaldehyde yield from the $\mathrm{O}_{3}$ + Wall reaction was used as an additional tuning parameter. With the corrections, the modeled $\mathrm{O}_{3}$ matches that observed very well, with average best fit slope of 1.00 and $r^{2}$ of 0.99 . The corresponding values for acetaldehyde are 1.02 and 0.86 .

The other tuning parameters in the model were used to estimate $\mathrm{OH} \cdot$ concentration. Specifically, an overall $\mathrm{OH} \cdot+\mathrm{X}$ loss rate (or $\mathrm{OH}$ reactivity) of $2 \mathrm{~s}^{-1}$ (or $\tau=0.5 \mathrm{~s}$ ) was assumed, as was a continuous source of nitrous acid, HONO, from the Teflon ${ }^{\circledR}$ surfaces (Rohrer et al., 2005). Photolysis of that $\mathrm{HONO}$ and of the modeled $\mathrm{O}_{3}$ were assumed to be the only $\mathrm{OH} \cdot$ sources. While the resulting $\mathrm{OH} \cdot$ concentration is not well constrained, the modeled influence of $\mathrm{OH} \cdot$ on reactive species such as isoprene is consistent with that observed. No attempt was made to account for gas-wall partitioning of VOC reaction products, despite recognition that such partitioning is significant and can complicate interpretation of results from Teflon ${ }^{\circledR}$ chambers (Matsunaga and Ziemann, 2010; Krechmer et al., 2016). For species that partition reversibly to the walls, the impact may be only an increase in the $\sim 30$ min effective chamber-ambient exchange time by an amount comparable to the $\sim 10 \mathrm{~min}$ timescale for reaching equilibrium for photochemically generated oxidation products as reported by Krechmer et al. (2016). Overall, the improved understanding of the CAGE chambers in general and the CSTR OD model in particular that came from the chamber-ambient comparison experiment increases the accuracy with which changes in captive particles can be connected with the responsible environmental conditions.

\section{Particle addition and sampling strategy}

To quantify particle growth rates and connect them with the responsible secondary aerosol formation and particle evaporation, sub- $0.1 \mu \mathrm{m}$ size-classified particles were repeatedly injected into the chambers throughout the 2-month study. Ammonium sulfate was selected due to its common use as a seed aerosol in chamber studies and because it often represents a significant component of atmospheric aerosols. Future studies are planned to evaluate the sensitivity of particle growth to the composition of the seed particles. To detect and accurately quantify changes that are typically between -1 and $10 \mathrm{~nm} \mathrm{~h}^{-1}$, the atomized aerosol was first sizeselected with a DMA to generate a monodisperse population. Throughout the experiments, an SMPS was used to measure the particle size distribution in each chamber twice per hour. The tracked mode size distributions were fitted using a lognormal function and the dry particle diameter, $D_{\text {mode }}$, and number concentration, $N$, parameters of the fits were used to calculate diameter growth rate and concentration loss rate, respectively. A new monodisperse mode was added as soon as 

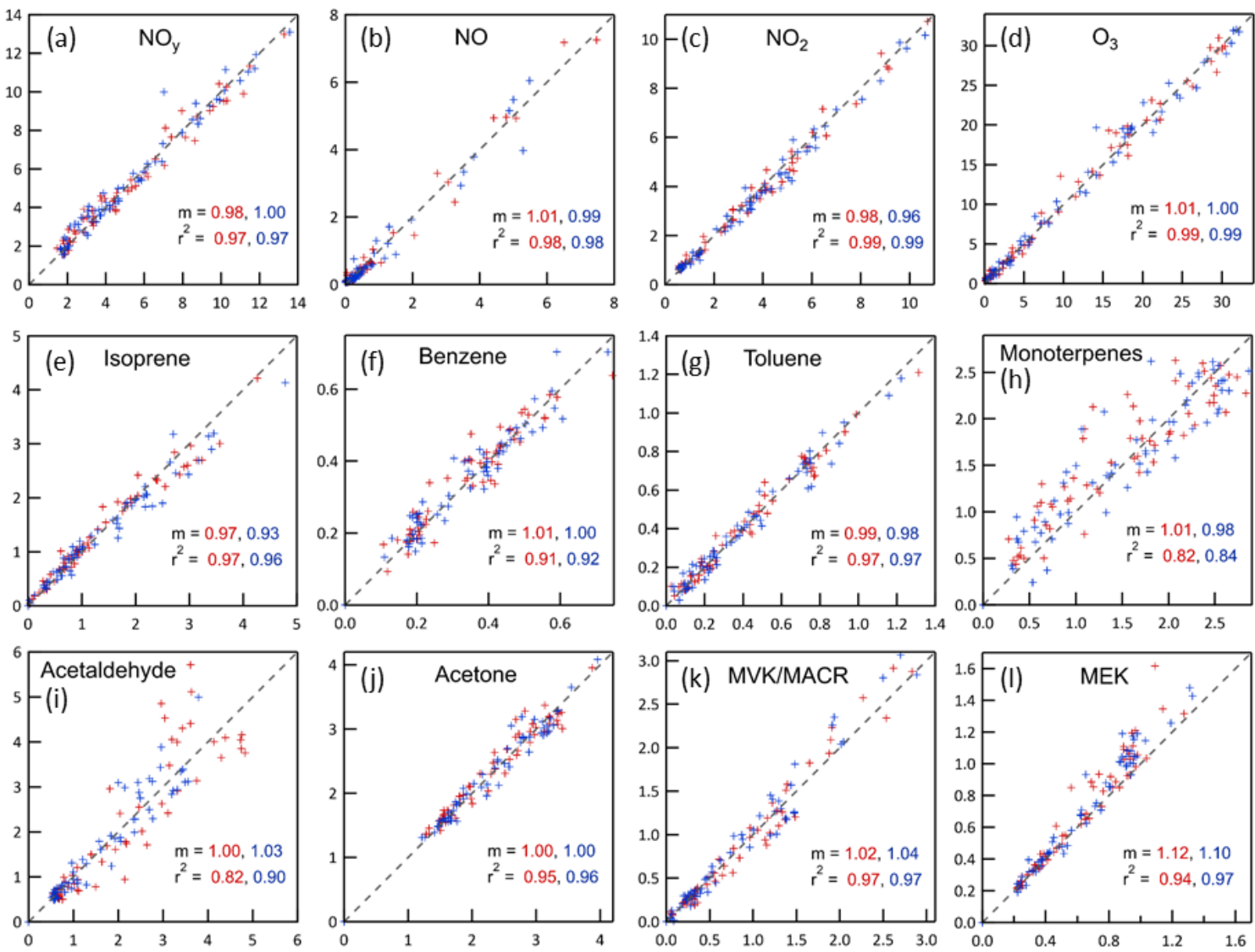

Figure 6. Relationships between mixing ratios ( $\mathrm{ppb}$ ) expected in the chambers calculated from the ambient time series using the CSTR OD model ( $x$-axes) and measured in the chambers ( $y$-axes). For all graphs, the red markers and text are for Chamber A and the blue are for Chamber B. The dashed lines shown in all graphs are $1: 1$ lines. The slopes, $m$, are for best fit lines forced through the origin. MVK/MACR $=$ methyl vinyl ketone/methacrolein, both of which are measured at the same mass by the PTR-MS. MEK = methyl ethyl ketone.

the previously injected mode became difficult to track. With this approach, growth rates were determined nearly $24 \mathrm{~h} \mathrm{~d}^{-1}$.

Condensable species that are produced are expected to be distributed among the particle population in the chamber. The division among those particles can depend on properties of the condensable species and of the particles, though results from this study suggest a simple particle surface area dependence. Because of competition for the condensable species among all particles in the chamber, the growth rate of the tracked mode will be affected by the total surface area concentration or condensation sink. To minimize that influence, an additional monodisperse ammonium sulfate mode centered at $0.3 \mu \mathrm{m}$ was maintained, with new injections triggered automatically each time the surface area concentration calculated from the SMPS-measured size distribution fell below $40 \mu \mathrm{m}^{2} \mathrm{~cm}^{-3}$. In addition to the injected ammonium sulfate particles, new particle formation events would sometimes occur inside the chambers just as they do in the atmosphere (Kulmala et al., 2004). The nucleation or NPF modes are broad relative to those injected, but are still typically narrow enough to track. The lower time series in Fig. 10 shows an example of the chamber size distributions measured by the SMPS over a $3.5 \mathrm{~d}$ period in September 2016. The size distributions measured just outside the chambers during the same period are shown in Fig. 10a to highlight the relative difficulty in connecting time variation in ambient measurements to the rate and cause(s) of particle growth. The modes labeled "IM" are the injected monodisperse ammonium sulfate modes, and those labeled "NM" are nucleation modes consisting of particles that formed and grew in the chamber. The repeated injections into the surface area mode (SAM) results in the roughly horizontal band centered at about $0.3 \mu \mathrm{m}$. To the right of the intensity graph is an $x-y$ representation of the size distribution measured at the time indicated by the rectangular box in the intensity graph. Also shown in the $x-y$ graph is the particle surface area concentration size distribution, which illustrates the extent to which the total concentration can be controlled by the SAM and is minimally impacted by the smaller particle tracked mode.

As noted above, the tracked modes were fitted with lognormal distributions to extract the time-dependent mode diameters. The result for the same $3.5 \mathrm{~d}$ period is shown in 


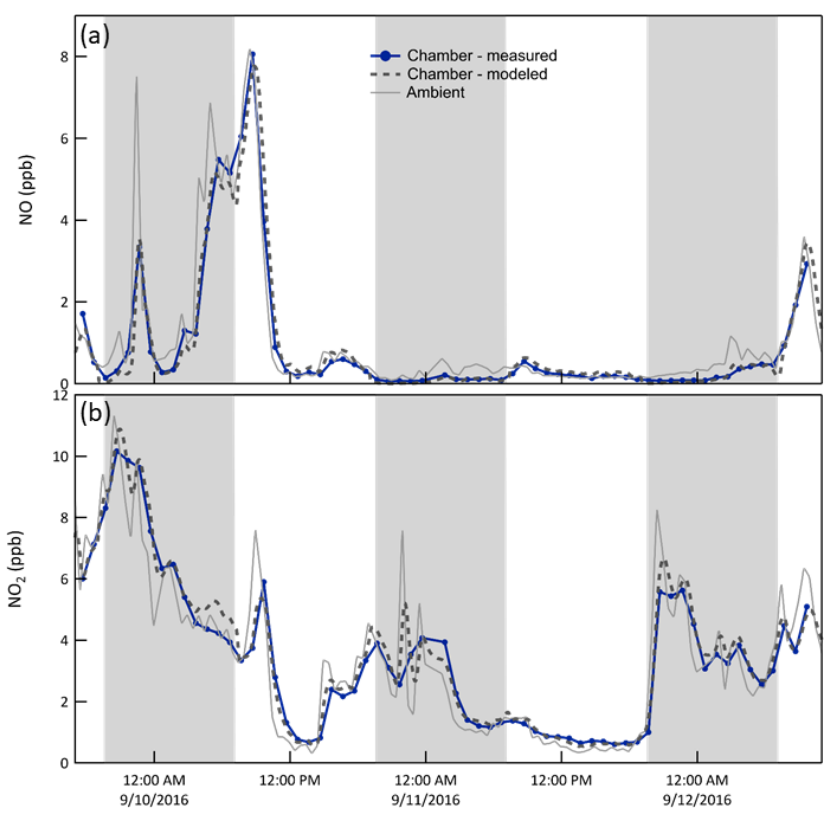

Figure 7. Time series of $\mathrm{NO}$ and $\mathrm{NO}_{2}$ mixing ratios (i) measured in chamber B (solid blue), (ii) expected in the chamber as calculated from the CSTR OD model (dashed), and (iii) measured outside (solid gray). Smoothing of the spikes in the ambient time series results from treatment of the chamber as a CSTR. The shaded bands represent nighttime.
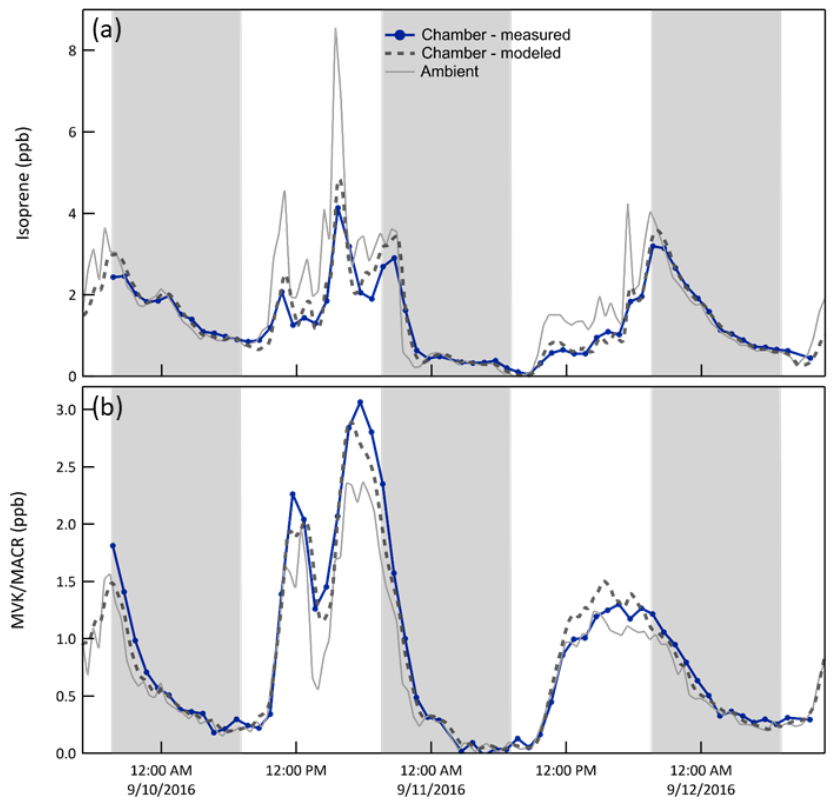

Figure 8. Mixing ratio time series of isoprene and its reaction products methyl vinyl ketone (MVK) + methacrolein (MACR) (i) measured and (ii) expected in Chamber B, and (iii) measured outside. Isoprene that enters through the ePTFE membrane reacts with $\mathrm{OH} \cdot$, $\mathrm{O}_{3}$, and $\mathrm{NO}_{3} \bullet$ in the chamber, resulting in a lower mixing ratio than outside. The shaded bands represent nighttime.
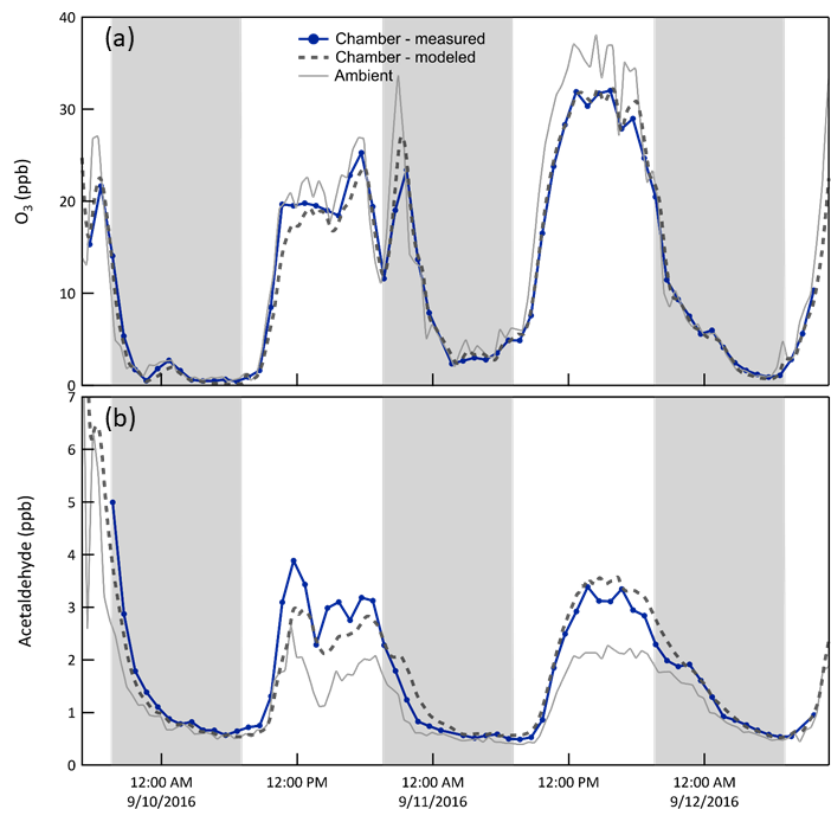

Figure 9. Time series of $\mathrm{O}_{3}$ (a) and acetaldehyde (b) mixing ratios (i) measured and (ii) expected in Chamber B, and (iii) measured outside. Ozone mixing ratios were slightly lower in the chamber than outside, which is believed to be the result of reactions with the Teflon ${ }^{\circledR}$ surfaces or with impurities on those surfaces. The loss rate constant was adjusted to match the observations. The shaded bands represent nighttime.

Fig. 11, where each of the curves represents one tracked mode. Different colors are used for different modes that overlapped in time and shaded bands are included to indicate nighttime. Figure 11a shows the integrated surface area concentration during the same period, with the sawtooth pattern resulting from the automatic injections of SAM particles each time the integrated surface area concentration fell below $40 \mu \mathrm{m}^{2} \mathrm{~cm}^{-3}$. The $x-y$ representation in Fig. 11c shows the lognormal fits to the same nucleation mode and two injected modes identified in Fig. 10. The compilation of the growth curves of all of the modes tracked during the 2016 study is presented in Fig. S6 in the Supplement.

For each tracked mode, the growth rate (GR) was calculated as the change in lognormal fit $D_{\text {mode }}$ between two successive measurements divided by the time difference between them, GR $=\Delta D_{\text {mode }} / \Delta t$, as presented in Fig. 12 for the same $3.5 \mathrm{~d}$ example period. The integrated surface area concentration time series shown in Fig. 11 is also included in Fig. 12. The vertical dashed lines in Fig. 12 correspond to the times at which surface area mode particles were injected. As is true for the full 2-month dataset, there is no obvious reflection of the surface area concentration pattern in the tracked mode growth rate curves, suggesting the range was sufficiently narrow and justifying the decision to use the calculated growth rates without any correction. An important feature in Fig. 12 is the similarity in GR among multiple 

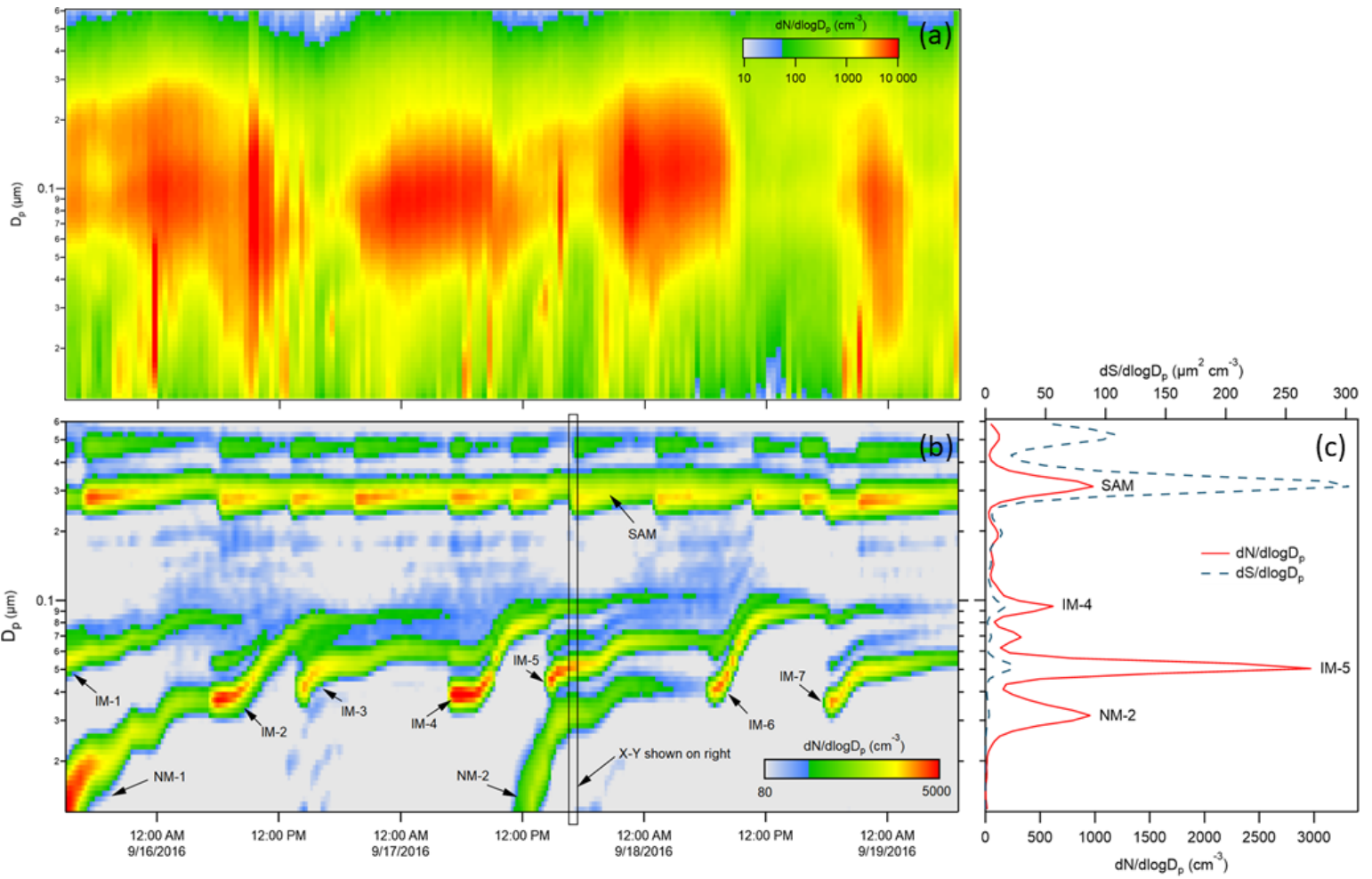

Figure 10. (a) Ambient aerosol size distribution time series over $3.5 \mathrm{~d}$ during the 2016 study. (b) Chamber A size distribution time series over the same period. $\mathrm{IM}=$ injected mode, $\mathrm{NM}=$ nucleation mode, $\mathrm{SAM}=$ surface area mode. (c) $x-y$ presentation of the size distribution measured at the time indicated by the rectangle in the intensity graph. $N=$ number concentration and $S=$ surface area concentration.

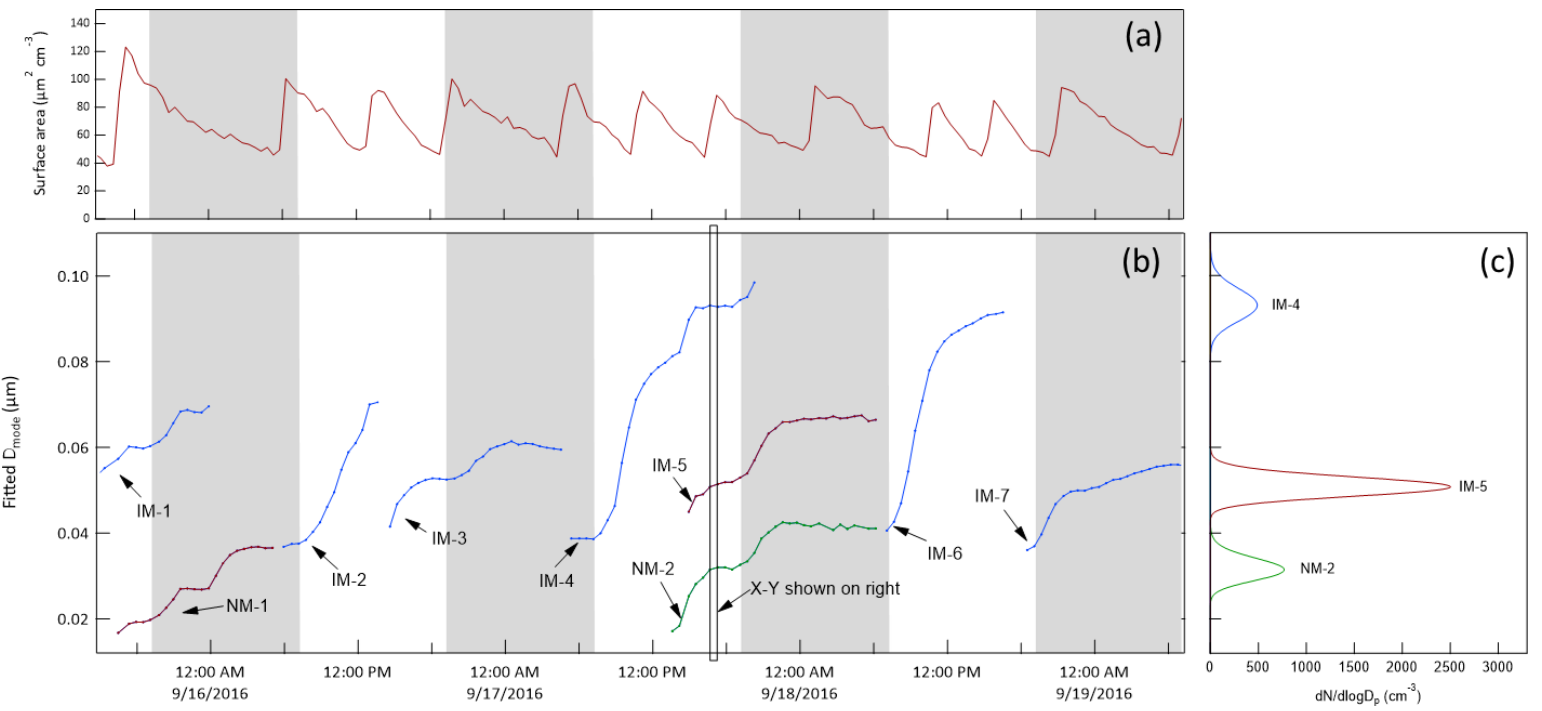

Figure 11. (b) Time series of the lognormal fit diameters of injected and nucleation modes identified in Fig. 10. Different colors are used when two or modes overlap in time. (c) Lognormal fits to the three modes tracked at the time indicated by the rectangle in the time series. (a) Integrated surface area concentration showing the result of slow decay followed by an automatic injection of $\sim 0.3 \mu \mathrm{m}$ particles each time the concentration fell below $40 \mu \mathrm{m}^{2} \mathrm{~cm}^{-3}$. The shaded bands represent nighttime. 
modes that were tracked simultaneously. This lack of size dependence suggests that condensational growth resulted in a rate of change of the volume of the particles that was proportional to their surface area. It simplifies the use of the data as a diameter-dependent correction would otherwise be required. Figure 13 shows the comparison of all growth rates calculated from simultaneously tracked modes. The general clustering around the $1: 1$ line and the lack of a strong size dependence supports the interpretation that the growth rate is independent of particle size.

The CAGE chambers were designed to permit experiments on captive aerosols for periods ranging from hours to more than a day. For the approach employed with some chambers of continuously adding and extracting equal flow rates, the particle lifetime would be too short if flow rates comparable to $Q_{\text {ex }}$ were used ( $\tau \sim 30 \mathrm{~min}$ ), while the gas-phase composition would differ too much from that outside if a much lower flow rate was used. Thus, by only exchanging the gases and not the particles across the gas-permeable membrane it is possible to conduct long-duration experiments under ambient conditions. Particle retention was further increased by rotating the chambers and by taking steps to minimize static charge on the Teflon ${ }^{\circledR}$ surfaces. Figure 14 summarizes the resulting distribution of lifetimes measured for different particle size populations and identifies the techniques and instruments used to quantify them. The three histograms represent particle lifetime distributions for distinct particle populations. As expected, loss rates are lowest and lifetimes highest for the $0.3 \mu \mathrm{m}$ particles that are in the size range at which the combined influence of diffusional and settling losses reaches a minimum. The average lifetime of bioaerosol particles with an average diameter of $2.4 \mu \mathrm{m}$ was $3.9 \mathrm{~h}$. Even neglecting losses due to sample flow extraction and electrostatic attraction, a lifetime of less than $1 \mathrm{~h}$ would be expected for a non-rotating chamber with the same $0.53 \mathrm{~m}$ radius and the same $2.4 \mu \mathrm{m}$ particles, which have a settling velocity of about $0.65 \mathrm{~m} \mathrm{~h}^{-1}$. Loss rates were typically highest during the daytime as solar heating promoted convection in the chambers.

Simply taking the average of the lifetimes for the three particle populations gives a particle lifetime of $6.0 \mathrm{~h}$. This is quite high for such a small chamber with a correspondingly high surface area to volume ratio. In fact, it is higher than those reported for much larger chambers used to study secondary aerosol formation, as is presented in Table 1, which combines the data for CAGE with other loss rates summarized by Wang et al. (2014). A caveat of the simple comparison with other chambers is that for CAGE the lifetimes were averaged over daytime and nighttime conditions, whereas for at least some of the other chambers the values were determined during daytime or when artificial lights were on.

\section{Results and discussion: connecting gas-phase and aerosol-phase measurements with aerosol production estimates}

Quantifying secondary aerosol formation in a chamber by diameter growth rate as is done here is atypical. Almost all chamber studies instead measure and report the change in particle volume or mass concentration over time. The result can conveniently be related to secondary aerosol mass yields, which can then be used in atmospheric models that predict aerosol production following reaction of various precursors. However, traditional chamber experiments often use precursor concentrations much higher than observed at locations such as JSF, particularly at times corresponding to the growth rate minima commonly observed in the early morning and late afternoon. Evidence of the difficulty of tracking secondary aerosol mass production in ambient concentration chambers such as these is demonstrated in Fig. 15, which shows the GR time series from Fig. 12 together with the organic aerosol production rate, $\mathrm{d} M_{\mathrm{org}} / \mathrm{d} t$, calculated from HR-ToF-AMS measurements. Though production of inorganic sulfate and nitrate aerosol could also contribute to the total aerosol production rate, the organic component is expected to dominate at forested sites in general and, as is shown in Fig. S7 in the Supplement, was found to contribute an average of about $74 \%$ of the ambient non-refractory submicron mass concentration during this study. The rate of change of organic aerosol mass concentration in the chambers was first corrected for losses due to flow extraction and wall deposition by normalizing with respect to the concurrently measured sulfate aerosol concentration,

$$
\frac{\mathrm{d} M_{\mathrm{org}}}{\mathrm{d} t}=\frac{\left(M_{\mathrm{org}}\right)_{i+1}-\left(M_{\mathrm{org}}\right)_{i} \frac{\left(M_{\mathrm{SO}_{4}}\right)_{i+1}}{\left(M_{\mathrm{SO}_{4}}\right)_{i}}}{t_{i+1}-t_{i}} .
$$

Data were used only from those periods during which $M_{\mathrm{SO}_{4}}$ exhibited the characteristic exponential decay expected as the initially high concentration from an ammonium sulfate SAM injection falls due to a constant loss rate. Figure 15a shows those decay profiles and corresponding loss time constants. Though averaging the results over longer time periods would reduce the noise, it would also reduce the utility of the data, as the time dependence would be obscured.

The diel profile of growth rate averaged over the full study period is shown in Fig. 16. An initial observation of the overall pattern is that the average GR is positive for every hour of the day. If growth resulted primarily from equilibrium partitioning of semi-volatile organics, the GR would be positive as the concentration of those gas-phase species increased with time and negative when they decreased, with an average at a fixed location over a long enough period close to zero. The combination of the observation that GR is diameterindependent and that it is almost always positive suggests that the species responsible for much of the growth had very 

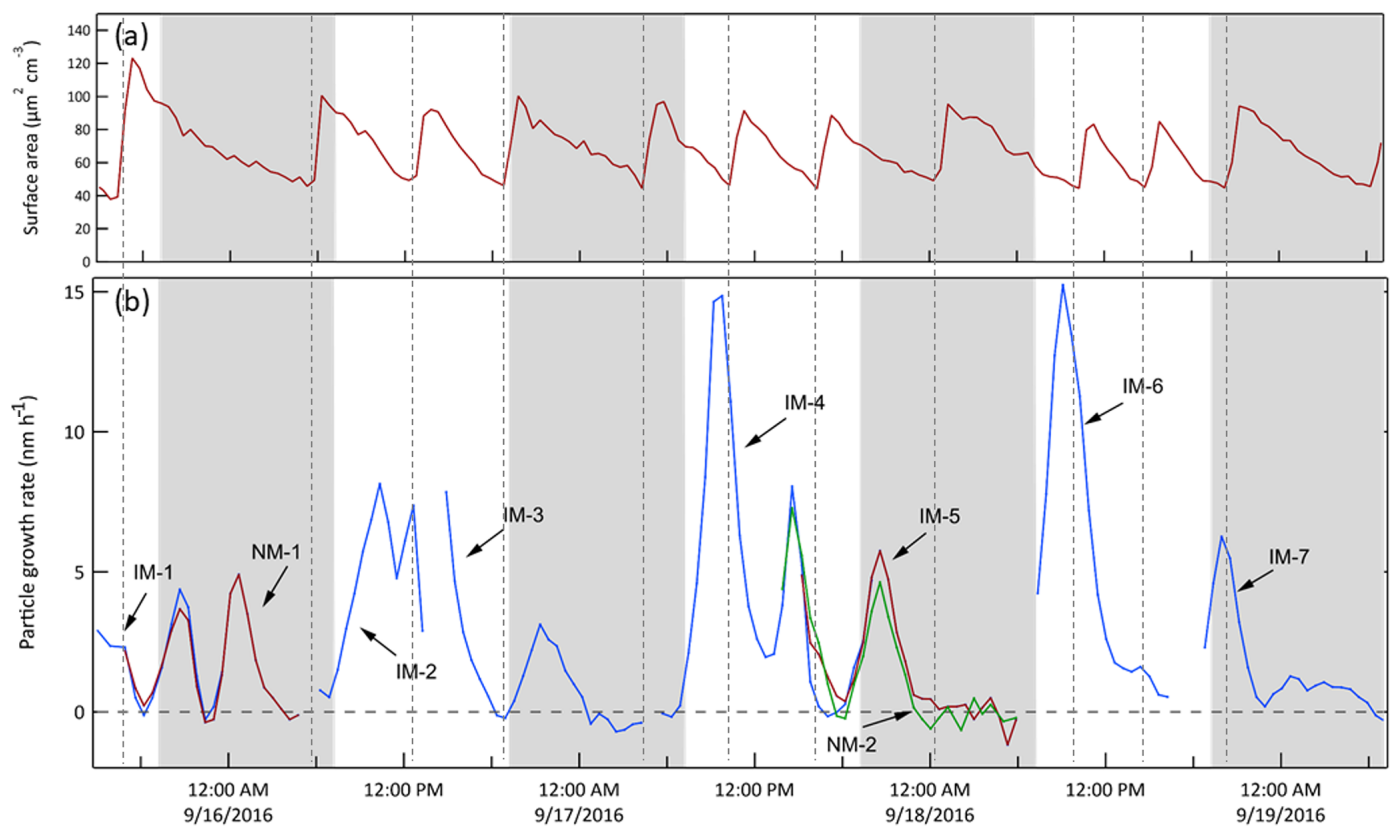

Figure 12. Particle growth rates calculated from the time series of lognormal fit diameters shown in Fig. 11. The different colors correspond to those used in Fig. 11. The integrated surface area concentration time series shown in Fig. 11 is included here to note the absence of any obvious reflection of that pattern in the growth rates. The shaded bands represent nighttime.

Table 1. Comparison of chamber particle loss rates. Copied from Wang et al. (2014) with CAGE data added.

\begin{tabular}{lrlrrl}
\hline Chamber & $\begin{array}{r}\text { Volume } \\
\left(\mathrm{m}^{3}\right)\end{array}$ & $\begin{array}{l}\text { Wall } \\
\text { material }\end{array}$ & $\begin{array}{r}\text { Wall loss } \\
\text { rate }\left(\mathrm{h}^{-1}\right)\end{array}$ & $\begin{array}{r}\text { Particle } \\
\text { lifetime }(\mathrm{h})\end{array}$ & Reference \\
\hline CAGE & 1 & FEP & 0.17 & 6.0 & This work \\
GIG-CAC & 30 & FEP & 0.17 & 5.9 & Wang et al. (2014) \\
PSI & 27 & FEP & 0.21 & 4.8 & Paulsen et al. (2005) \\
Caltech & 28 & FEP & 0.20 & 5.0 & Cocker et al. (2001) \\
UCR & 90 & FEP & 0.29 & 3.4 & Carter et al. (2005) \\
EUPHORE & 200 & FEP & 0.18 & 5.6 & Martin-Reviejo and Wirtz (2005) \\
SAPHIR & 270 & FEP & 0.27 & 3.7 & Rollins et al. (2009) \\
CMU & 12 & FEP & 0.40 & 2.5 & Donahue et al. (2012) \\
\hline
\end{tabular}

low volatility and irreversibly condensed on the particles at a rate controlled mostly by their surface area.

The bimodality evident in the histogram in Fig. 16 results from active $\mathrm{OH} \cdot$-driven aerosol production during the day and $\mathrm{NO}_{3} \cdot$ - and $\mathrm{O}_{3}$-driven production at night. Figure 17 shows the daily profiles of the mean and $25 \mathrm{th} / 75$ th percentile range for the calculated in-chamber concentrations of the important oxidants $\left(\mathrm{OH} \cdot, \mathrm{O}_{3}\right.$, and $\left.\mathrm{NO}_{3} \cdot\right)$ and most important anthropogenic (toluene) and biogenic (isoprene and the monoterpenes) secondary organic aerosol precursors. The average GR profile from Fig. 16 is included in each of the columns of the graphs in Fig. 17 to more clearly show the connection between the gas-phase concentrations and the resulting aerosol production. The similarity between the $\mathrm{OH}$ • and daytime GR profiles and between the $\mathrm{NO}_{3} \cdot$ and nighttime GR profiles is apparent. The leftward shift in the day- time GR profile relative to that of $\mathrm{OH} \cdot$ and the rightward shift in the nighttime GR profile relative to that of $\mathrm{NO}_{3} \cdot$ is believed to result from variation in the hydrocarbon precursor concentrations, as the aerosol production rate is dependent on the product of the oxidant and precursor concentrations. Most importantly, the concentrations of both toluene and the monoterpenes decrease during the morning as the mixed layer deepens and then increase in the early evening as the pattern reverses and vertical mixing is limited.

Support for the broad interpretation of the relationship between the patterns in the GR and gas-phase concentrations in Fig. 17 comes from estimates of secondary aerosol production rate with the CSTR 0D model. The results are used to further interpret temporal variability in GR during the day or night and between days and to assess the rates of aerosol production resulting from specific oxidant and precursor combi- 


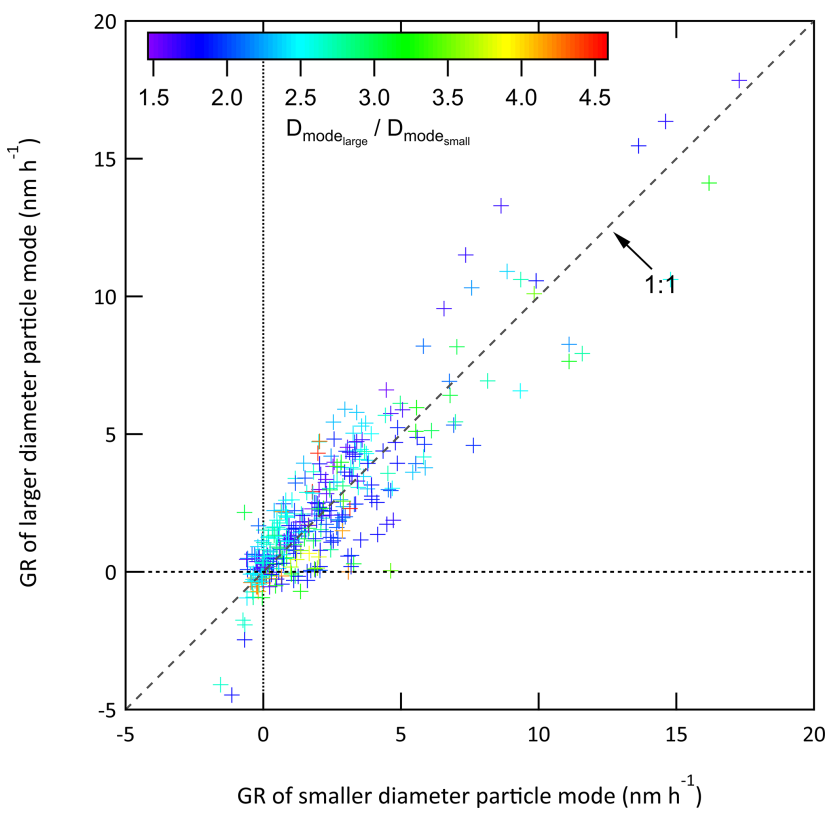

Figure 13. Comparison of all pairs of growth rates calculated for multiple modes tracked at the same time. The GR of the smaller diameter mode is plotted on the $x$-axis and that of the larger diameter mode on the $y$-axis. The ratio of the diameter of the lognormal fit of the larger particle mode to that of the smaller particle mode is indicated by marker color.

nations. The estimated aerosol production at each time step is calculated as

$P_{\mathrm{SA}}=\frac{1}{N_{\mathrm{A}}} \sum_{i} k_{i}[$ Precursor] [Oxidant $] \mathrm{MW}_{\text {precursor }} Y_{i}{ }^{\prime}$,

where $P_{\mathrm{SA}}$ is the secondary aerosol production rate, $N_{\mathrm{A}}$ is Avogadro's number, $k_{i}$ [Precursor][Oxidant] is the reaction rate between a precursor and oxidant, $\mathrm{MW}$ is the molecular weight of the precursor, and $Y_{i}^{\prime}$ is an effective aerosol production yield that was adjusted such that (arbitrarily) the value of $P_{\mathrm{SA}}$ (in $\mu \mathrm{g} \mathrm{m}^{-3} \mathrm{~h}^{-1}$ ) closely matched that of GR (in $\mathrm{nm} \mathrm{h}^{-1}$ ). The goal was to evaluate how well the model could explain the time dependence of the observed growth and not to retrieve mass-based aerosol yields. As is shown in Fig. 18, the calculated production rate captures the variation in GR over the same example $3.5 \mathrm{~d}$ period highlighted in Figs. 10, 11, 12 , and 15. During this period and for the remainder of the study, the quality of the fit to the nighttime measurements of GR was generally significantly better than that for the daytime measurements. Among the contributors to uncertainty in the daytime estimates are the poor constraint on $\mathrm{OH} \cdot$ concentration and the exclusion of some VOC precursors such as the xylenes that react efficiently only with $\mathrm{OH} \cdot$ and for which measured concentrations were very noisy and rarely above the detection limit of the PTR-MS. Furthermore, no attempt was made to estimate the concentrations or impacts of unmeasured intermediate-volatile and semi-volatile organic

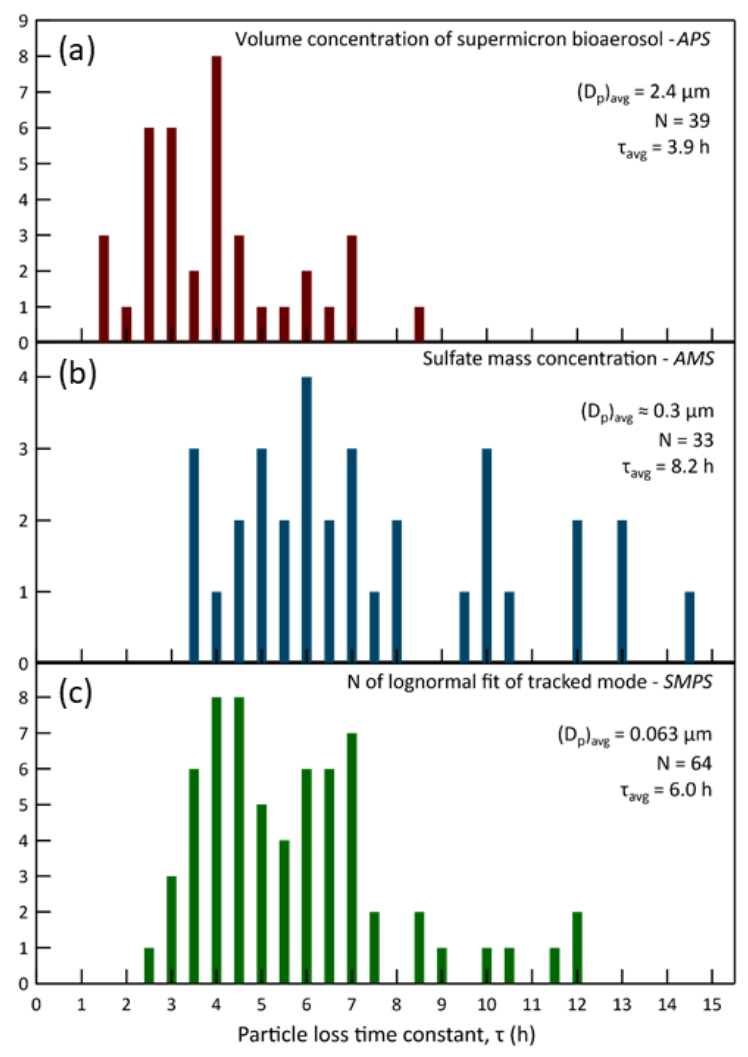

Figure 14. Exponential time constants for particle loss in the chambers during the 2016 study. Graph (a) presents the distribution of lifetimes of injected bioaerosol particles, which had an average diameter of $2.4 \mu \mathrm{m}$. The loss rates were determined from exponential decay fits to the supermicron volume concentration that was calculated from measurements by an APS. Graph (b) presents the distribution of lifetimes of $0.3 \mu \mathrm{m}$ diameter ammonium sulfate particles intermittently injected to maintain a stable surface area concentration in the chambers. The loss rates were determined from exponential decay fits to the sulfate mass concentration measured with an HR-ToF-AMS. Graph (c) presents the distribution of lifetimes of "tracked mode" particles having a study-average diameter of $0.063 \mu \mathrm{m}$. The loss rates were determined from exponential decay fits to the number concentration parameter of lognormal fits to the narrow mode distributions measured with an SMPS. The $y$-axis values are the number of times the calculated loss rates fell within each $0.5 \mathrm{~h}$ bin.

compounds (IVOC and SVOC). The profile of the nighttime production rate was relatively insensitive to how it was partitioned between SOA production by $\mathrm{O}_{3}$ and by $\mathrm{NO}_{3} \cdot$.

Though the characteristic bimodal growth rate pattern persisted throughout the 2-month study, there was a significant shift in the relative amplitudes of the daytime and nighttime maxima. The pattern change is evident in the contrast between the summer (15 August-21 September) and fall (22 September-14 October) hourly average GR profiles shown in Fig. 19. Unfortunately, explanation of the shift is difficult because measurement of the VOCs and all trace gases ex- 


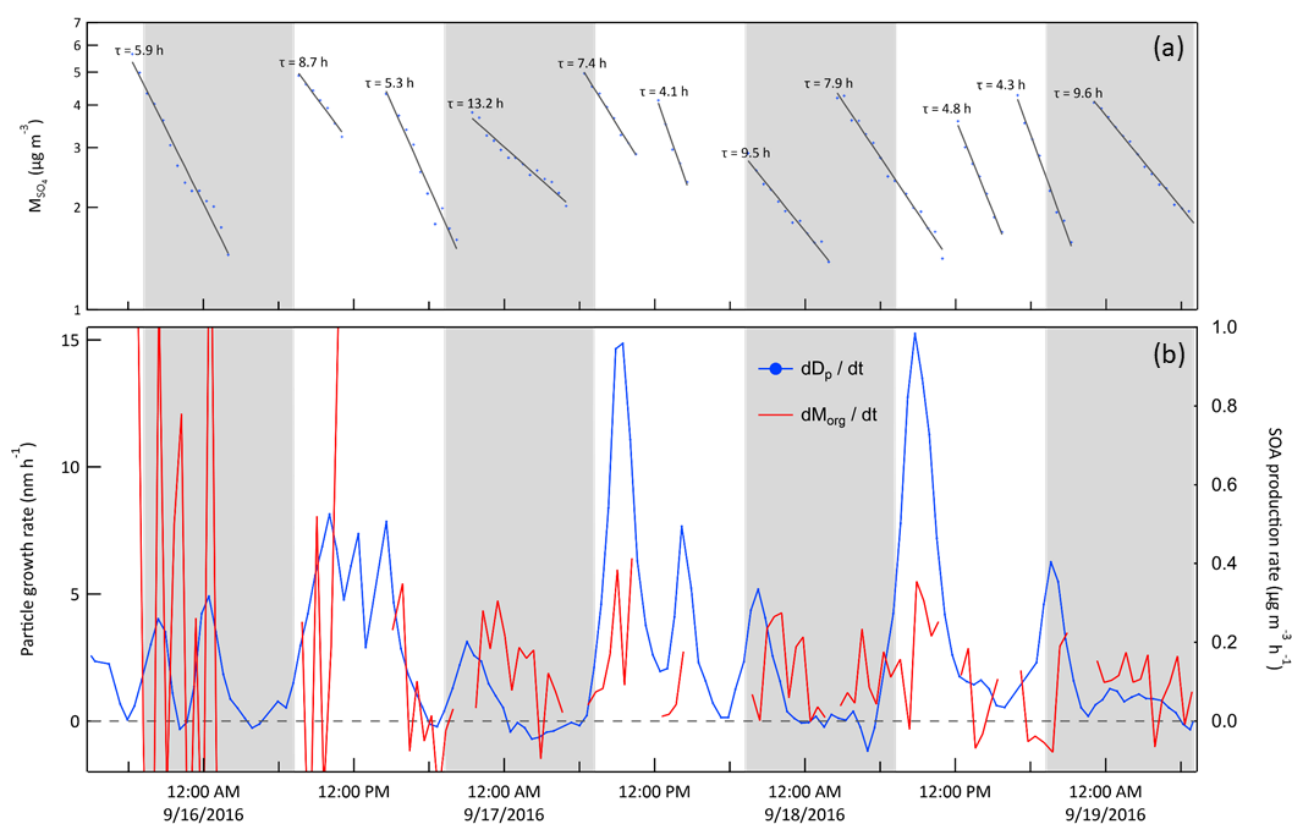

Figure 15. (a) Sulfate mass concentration in Chamber A measured with the HR-ToF-AMS during the same $3.5 \mathrm{~d}$ example period as in Figs. 10, 11, and 12. The lines and time constants are for the exponential decay fits to the concentrations. (b) Averaged diameter growth rate from Fig. 12 (blue) and calculated rate of change of organic aerosol mass concentration (red). The rate of change of the organic mass concentration was corrected for loss using the sulfate mass using Eq. (2). The contrast between the two highlights the challenge in quantifying secondary aerosol production under ambient conditions using measurements of aerosol volume or mass concentration and motivates instead tracking narrow size distribution modes. The shaded bands represent nighttime.

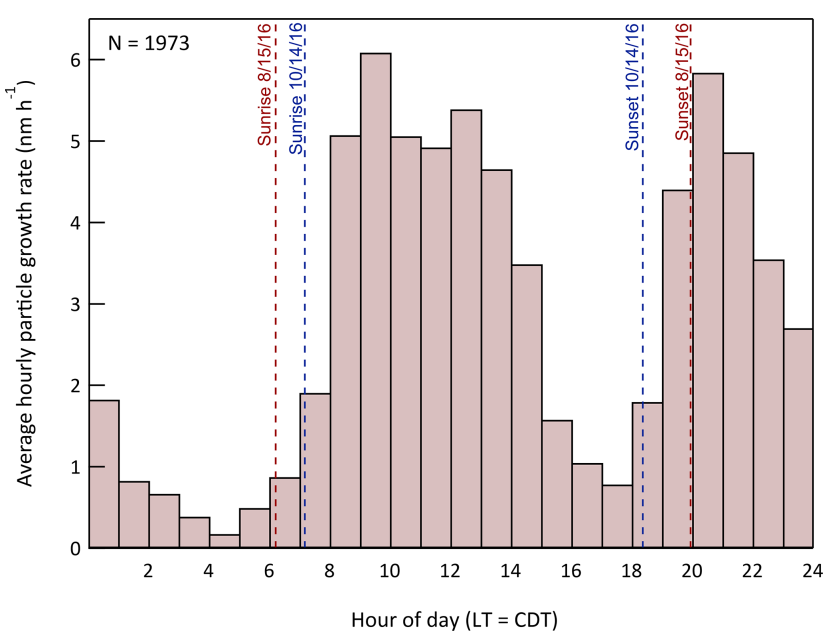

Figure 16. Hourly average particle growth rate during the study. A total of 1973 values were used to construct the histogram. The times of sunrise and sunset for the first (15 August) and last (14 October) day of measurements are also indicated.

cept $\mathrm{O}_{3}$ ended on 22 September. At least some of the shift in nighttime particle growth is explained by a corresponding trend in nighttime $\mathrm{O}_{3}$, with higher values more frequent later in the study. The average GR from 19:00 to midnight local time is correlated with the average $\mathrm{O}_{3}$ mixing ratio for the same time interval, with an $r^{2}$ of 0.60 (Fig. S8 in the Supplement). The correlation likely encompasses more rapid VOC oxidation due to the increased $\mathrm{O}_{3}$ and to the increased $\mathrm{NO}_{3}$. that forms from reaction of $\mathrm{O}_{3}$ and $\mathrm{NO}_{2}$. Additional insight into the short-term and seasonal variation in particle growth could come from longer term studies with more comprehensive gas-phase measurements that include monoterpene speciation.

\section{Conclusions}

The Captive Aerosol Growth and Evolution (CAGE) chambers were characterized during a field study at a forested site outside of Houston, TX. The CAGE chamber differs from most other Teflon ${ }^{\circledR}$ chambers in its portability, use of solar illumination to drive photochemistry, rotation along its horizontal axis, and exchange of air with the surroundings through a permeable ePTFE membrane. Chamber-ambient comparison for a range of measured organic and inorganic gases showed that concentrations in the chambers were similar to those in the air surrounding them, with an effective exchange flow rate into and out of each chamber through the permeable membrane of about $33 \mathrm{~L} \mathrm{~min}^{-1}$. Results from those chamber-ambient characterization experiments were used to validate a CSTR OD model that uses measured concentrations of gases in ambient air to calculate concentrations 

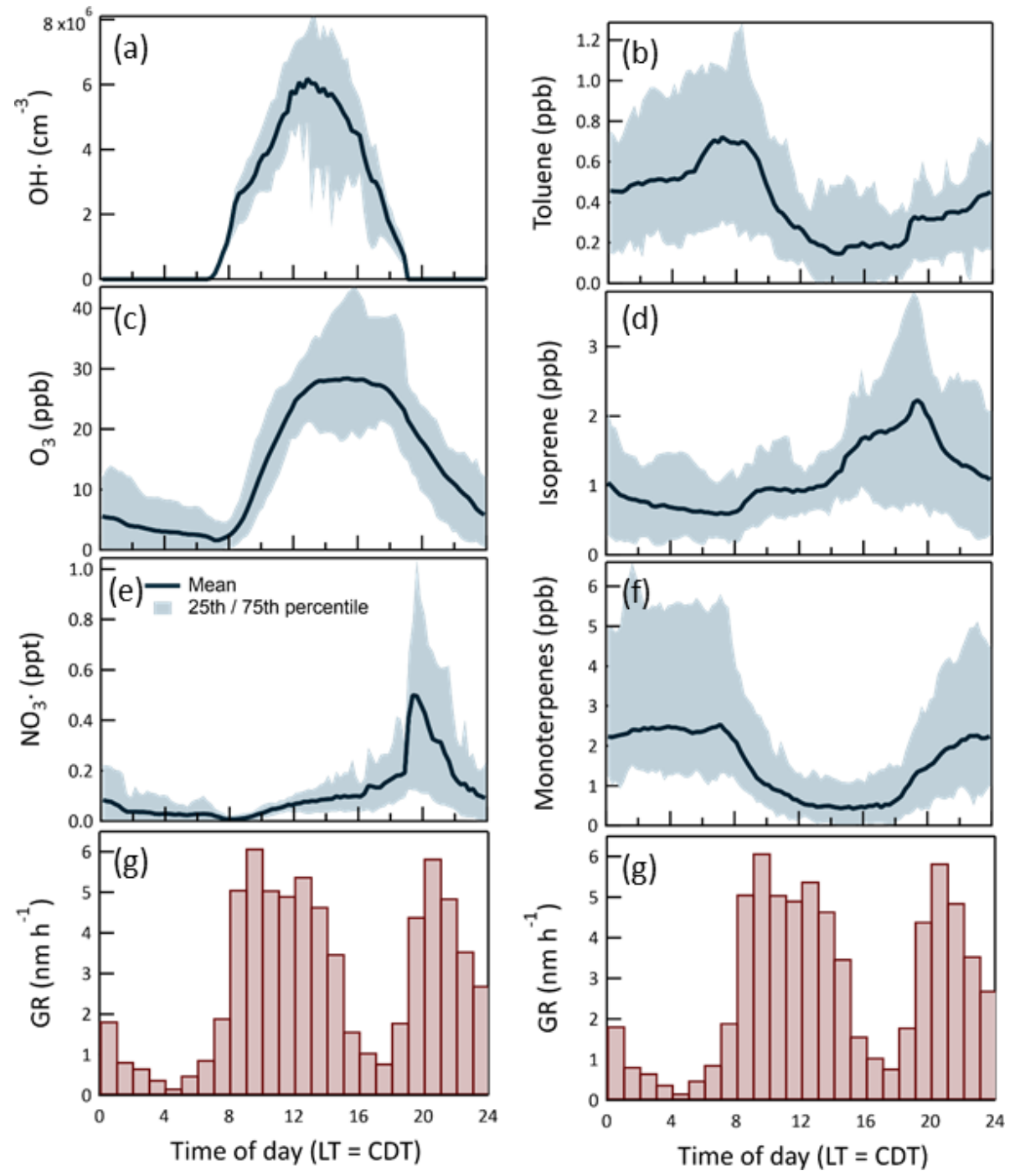

Figure 17. Time of day-dependent mean and 25th/75th percentiles for the most important oxidants (a), (c), (e) and secondary organic aerosol precursors (b), (d), (f). Hourly averaged particle growth rates during the 2016 study are shown at the bottom (g). A total of 1973 values were used to construct the histogram.

of measured and unmeasured species inside the chamber. Those calculated gas concentrations were subsequently used to estimate production rates of low volatility compounds that contribute to secondary aerosol formation and particle growth. Narrow modes of sub- $0.1 \mu \mathrm{m}$ diameter ammonium sulfate seed particles were repeatedly injected into the reaction chambers and their growth rates measured $24 \mathrm{~h} \mathrm{~d}^{-1}$ while they were exposed to conditions mirroring those outside. A mode of larger particles was maintained in each chamber to provide stable surface area concentrations and, consequently, stable competition for condensable species.

Particle growth rate was measured continuously throughout the 2-month study. The observations that particle growth rate was independent of particle size during periods when more than one mode was tracked simultaneously, and that the time of day growth rates averaged over the study were all positive suggests that particle growth was caused mostly by low volatility species that condensed irreversibly. The bimodality of the diel particle growth rate pattern results from late morning maxima from $\mathrm{OH} \cdot$ chemistry and evening maxima from $\mathrm{O}_{3}$ and $\mathrm{NO}_{3} \cdot$ chemistry. The diel pattern had a seasonal dependence that should be further investigated. The temporal pattern of secondary aerosol production rate estimated using the CSTR 0D model was similar to that of the measured particle growth rate, with an $r^{2}$ between the two time series of 0.64. Ongoing and future studies with CAGE chambers are designed to quantify the sensitivities of particle growth to perturbations of ambient air caused by the addition of one or more gases. 


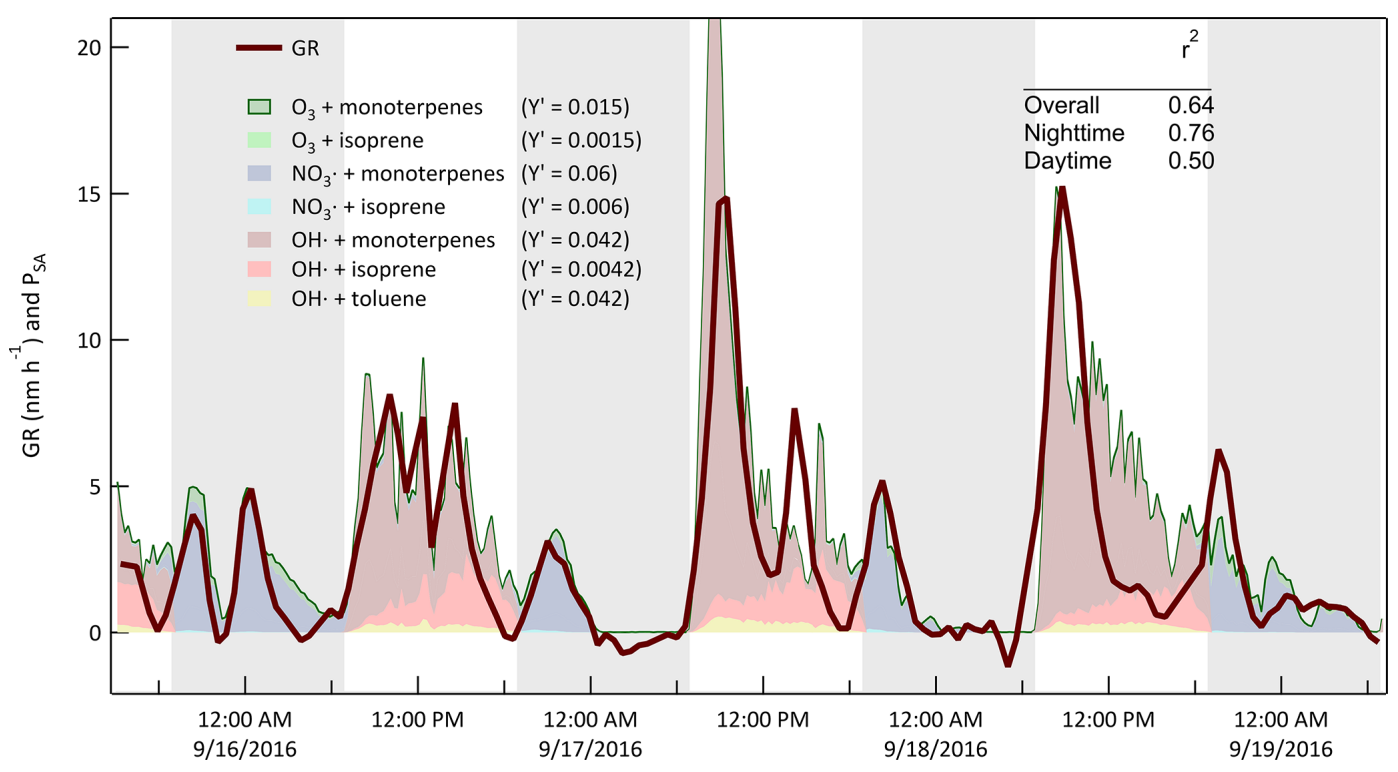

Figure 18. Measured diameter growth rate $(\mathrm{GR})$ and calculated secondary aerosol production rate $\left(P_{\mathrm{SA}}\right)$ for the same $3.5 \mathrm{~d}$ example period described above. Effective aerosol yields for the reactions considered were adjusted to minimize differences between the values of GR (in $\mathrm{nm} \mathrm{h}^{-1}$ ) and $P_{\mathrm{SA}}$ (in $\mu \mathrm{g} \mathrm{m}^{-3} \mathrm{~h}^{-1}$ ). The shaded bands represent nighttime.

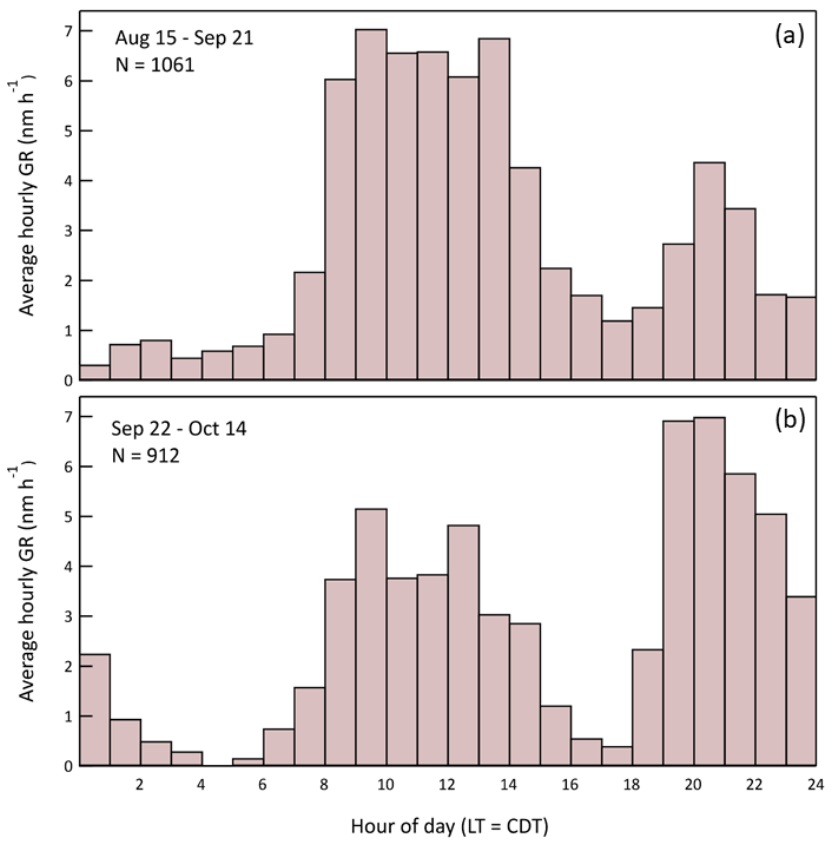

Figure 19. Hourly average particle growth rates during the late summer (a) and early fall (b) portions of the study. A shift in the relative importance of daytime and nighttime growth occurred between the start and end of the project.

Code availability. The software code for this paper is available from the corresponding author.
Data availability. The data for this paper are available from the corresponding author.

Supplement. The supplement related to this article is available online at: https://doi.org/10.5194/amt-14-3351-2021-supplement.

Author contributions. CLS and DRC prepared the manuscript with contributions from all co-authors. DRC, JMM, and CFM operated the CAGE chambers during the field study and analyzed the resulting dataset. MHE, JHF, RJS, SU, HWW, AATB, RJG, MT, SMK, and JLS participated in the field study and measured gas-phase and/or aerosol-phase concentrations and properties that were used in the characterization of the CAGE chambers.

Competing interests. The authors declare that they have no conflict of interest.

Acknowledgements. Funding support for operation of the CAGE chambers and the bioaerosol experiments was provided by the Defense Threat Reduction Agency through grant HDTRA1310184. Support for the University of Houston, Rice University, and Baylor University researchers was provided by the National Science Foundation through grants AGS-1552086 and AGS-1552077. We thank the Texas A\&M Forest Service and the staff at the WG Jones State Forest headquarters for their assistance and for providing space for the chambers and trailers. We also thank the many undergraduate and graduate students at Texas A\&M University who assisted in the construction and testing of the CAGE chambers described here and of their predecessors. 
Financial support. This research has been supported by the Defense Threat Reduction Agency (grant no. HDTRA1310184) and the National Science Foundation (grant nos. AGS-1552086 and AGS-1552077).

Review statement. This paper was edited by Mingjin Tang and reviewed by three anonymous referees.

\section{References}

Asgharian, B. and Moss, O. R.: Particle Suspension in a Rotating Drum Chamber When the Influence of Gravity and Rotation are Both Significant, Aerosol Sci. Technol., 17, 263-277, https://doi.org/10.1080/02786829208959575, 1992.

Barnes, I., Becker, K. H., and Mihalopoulos, N.: An FTIR product study of the photooxidation of dimethyl disulfide, J. Atmos. Chem., 18, 267-289, https://doi.org/10.1007/BF00696783, 1994.

Becker, K. H.: The European photoreactor EUPHORE, Final report of the EC-Project, contract No EV5V-CT92-0059, 1996.

Becker, K. H.: Overview on the development of chambers for the study of atmospheric chemical processes, in: Environmental Simulation Chambers: Application to Atmosperic Chemical Processes, edited by: Barnes I. and Rudzinski K. J., Vol 62, Springer, Dordrecht, 26 pp., https://doi.org/10.1007/1-40204232-9_1, 2006.

Bonn, B., Sun, S., Haunold, W., Sitals, R., van Beesel, E., dos Santos, L., Nillius, B., and Jacobi, S.: COMPASS - COMparative Particle formation in the Atmosphere using portable Simulation chamber Study techniques, Atmos. Meas. Tech., 6, 3407-3423, https://doi.org/10.5194/amt-6-3407-2013, 2013.

Brotto, P., Repetto, B., Formenti, P., Pangui, E., Livet, A., Bousserrhine, N., Martini, I., Varnier, O., Doussin, J. F., and Prati, P.: Use of an atmospheric simulation chamber for bioaerosol investigation: a feasibility study, Aerobiologia (Bologna), 31, 445-455, https://doi.org/10.1007/s10453-015-9378-2, 2015.

Carter, W. P. L., Cocker III, D. R., Fitz, D. R., Malkina, I. L., Bumiller, K., Sauer, C. G., Pisano, J. T., Bufalino, C., and Song, C.: A new environmental chamber for evaluation of gas-phase chemical mechanisms and secondary aerosol formation, Atmos. Environ., 39, 7768-7788, https://doi.org/10.1016/j.atmosenv.2005.08.040, 2005.

Chung, A., Lall, A. A., and Paulson, S. E.: Particulate emissions by a small non-road diesel engine: Biodiesel and diesel characterization and mass measurements using the extended idealized aggregates theory, Atmos. Environ., 42, 2129-2140, https://doi.org/10.1016/j.atmosenv.2007.11.050, 2008.

Cocker, D. R., Flagan, R. C., and Seinfeld, J. H.: Stateof-the-art chamber facility for studying atmospheric aerosol chemistry, Environ. Sci. Technol., 35, 2594-2601, https://doi.org/10.1021/es0019169, 2001.

de Gouw, J. and Warneke, C.: Measurements of volatile organic compounds in the earth's atmosphere using proton-transferreaction mass spectrometry, Mass Spectrom. Rev., 26, 223-257, https://doi.org/10.1002/mas.20119, 2007.

De Haan, D. O., Brauers, T., Oum, K., Stutz, J., Nordmeyer, T., and Finlayson-Pitts, B. J.: Heterogeneous chemistry in the tropo- sphere: Experimental approaches and applications to the chemistry of sea salt particles, Int. Rev. Phys. Chem., 18, 343-385, https://doi.org/10.1080/014423599229910, 1999.

Donahue, N. M., Henry, K. M., Mentel, T. F., Kiendler-Scharr, A., Spindler, C., Bohn, B., Brauers, T., Dorn, H. P., Fuchs, H., Tillmann, R., Wahner, A., Saathoff, H., Naumann, K.-H., Mohler, O., Leisner, T., Muller, L., Reinnig, M.-C., Hoffmann, T., Salo, K., Hallquist, M., Frosch, M., Bilde, M., Tritscher, T., Barmet, P., Praplan, A. P., DeCarlo, P. F., Dommen, J., Prevot, A. S. H., and Baltensperger, U.: Aging of biogenic secondary organic aerosol via gas-phase $\mathrm{OH}$ radical reactions, P. Natl. Acad. Sci., 109, 13503-13508, https://doi.org/10.1073/pnas.1115186109, 2012.

Doussin, J. F., Ritz, D., Durand-Jolibois, R., Monod, A., and Carlier, P.: Design of an environmental chamber for the study of atmospheric chemistry: New developments in the analytical device, Analusis, 25, 236-242, https://doi.org/10.1016/S03654877(97)86083-4, 1997.

Duplissy, J., Enghoff, M. B., Aplin, K. L., Arnold, F., Aufmhoff, H., Avngaard, M., Baltensperger, U., Bondo, T., Bingham, R., Carslaw, K., Curtius, J., David, A., Fastrup, B., Gagné, S., Hahn, F., Harrison, R. G., Kellett, B., Kirkby, J., Kulmala, M., Laakso, L., Laaksonen, A., Lillestol, E., Lockwood, M., Mäkelä, J., Makhmutov, V., Marsh, N. D., Nieminen, T., Onnela, A., Pedersen, E., Pedersen, J. O. P., Polny, J., Reichl, U., Seinfeld, J. H., Sipilä, M., Stozhkov, Y., Stratmann, F., Svensmark, H., Svensmark, J., Veenhof, R., Verheggen, B., Viisanen, Y., Wagner, P. E., Wehrle, G., Weingartner, E., Wex, H., Wilhelmsson, M., and Winkler, P. M.: Results from the CERN pilot CLOUD experiment, Atmos. Chem. Phys., 10, 1635-1647, https://doi.org/10.5194/acp-10-1635-2010, 2010.

Glen, C. R.: Observations of secondary organic aerosol production and soot aging under atmospheric conditions using a novel environmental aerosol chamber, $\mathrm{PhD}$ thesis, Texas $\mathrm{A} \& \mathrm{M}$ University, 2010.

Glowacki, D. R., Goddard, A., Hemavibool, K., Malkin, T. L., Commane, R., Anderson, F., Bloss, W. J., Heard, D. E., Ingham, T., Pilling, M. J., and Seakins, P. W.: Design of and initial results from a Highly Instrumented Reactor for Atmospheric Chemistry (HIRAC), Atmos. Chem. Phys., 7, 53715390, https://doi.org/10.5194/acp-7-5371-2007, 2007.

Goldberg, L. J.: Naval biomedical research laboratory, programmed environment, aerosol facility, Appl. Microbiol., 21, 244-252, 1971.

Goldberg, L. J., Watkins, H. M. S., Boerke, E. E., and Chatigny, M. A.: The use of a rotating drum for the study of aerosols over extended periods of time, Am. J. Epidemiol., 68, 85-93, https://doi.org/10.1093/oxfordjournals.aje.a119954, 1958.

Guenther, A. B., Jiang, X., Heald, C. L., Sakulyanontvittaya, T., Duhl, T., Emmons, L. K., and Wang, X.: The Model of Emissions of Gases and Aerosols from Nature version 2.1 (MEGAN2.1): an extended and updated framework for modeling biogenic emissions, Geosci. Model Dev., 5, 1471-1492, https://doi.org/10.5194/gmd-5-1471-2012, 2012.

Hallquist, M., Wenger, J. C., Baltensperger, U., Rudich, Y., Simpson, D., Claeys, M., Dommen, J., Donahue, N. M., George, C., Goldstein, A. H., Hamilton, J. F., Herrmann, H., Hoffmann, T., Iinuma, Y., Jang, M., Jenkin, M. E., Jimenez, J. L., Kiendler-Scharr, A., Maenhaut, W., McFiggans, G., Mentel, Th. F., Monod, A., Prévôt, A. S. H., Seinfeld, J. H., Surratt, J. D., 
Szmigielski, R., and Wildt, J.: The formation, properties and impact of secondary organic aerosol: current and emerging issues, Atmos. Chem. Phys., 9, 5155-5236, https://doi.org/10.5194/acp9-5155-2009, 2009.

Hennigan, C. J., Miracolo, M. A., Engelhart, G. J., May, A. A., Presto, A. A., Lee, T., Sullivan, A. P., McMeeking, G. R., Coe, H., Wold, C. E., Hao, W.-M., Gilman, J. B., Kuster, W. C., de Gouw, J., Schichtel, B. A., Collett Jr., J. L., Kreidenweis, S. M., and Robinson, A. L.: Chemical and physical transformations of organic aerosol from the photo-oxidation of open biomass burning emissions in an environmental chamber, Atmos. Chem. Phys., 11, 7669-7686, https://doi.org/10.5194/acp11-7669-2011, 2011.

Hidy, G. M.: Atmospheric Chemistry in a Box or a Bag, Atmosphere, 10, 401, https://doi.org/10.3390/atmos10070401, 2019.

Hu, C., Cheng, Y., Pan, G., Gai, Y., Gu, X., Zhao, W., Wang, Z., Zhang, W., Chen, J., Liu, F., Shan, X., and Sheng, L.: A Smog Chamber Facility for Qualitative and Quantitative Study on Atmospheric Chemistry and Secondary Organic Aerosol, Chinese J. Chem. Phys., 27, 631-639, https://doi.org/10.1063/16740068/27/06/631-639, 2014.

Im, Y., Jang, M., and Beardsley, R. L.: Simulation of aromatic SOA formation using the lumping model integrated with explicit gas-phase kinetic mechanisms and aerosol-phase reactions, Atmos. Chem. Phys., 14, 4013-4027, https://doi.org/10.5194/acp14-4013-2014, 2014.

Jeffries, H., Fox, D., and Kamens, R.: Outdoor smog chamber studies: light effects relative to indoor chambers, Environ. Sci. Technol., 10, 1006-1011, https://doi.org/10.1021/es60121a016, 1976.

Kaltsonoudis, C., Jorga, S. D., Louvaris, E., Florou, K., and Pandis, S. N.: A portable dual-smog-chamber system for atmospheric aerosol field studies, Atmos. Meas. Tech., 12, 27332743, https://doi.org/10.5194/amt-12-2733-2019, 2019.

King, S. M., Rosenoern, T., Shilling, J. E., Chen, Q., and Martin, S. T.: Increased cloud activation potential of secondary organic aerosol for atmospheric mass loadings, Atmos. Chem. Phys., 9, 2959-2971, https://doi.org/10.5194/acp-9-2959-2009, 2009.

Klotz, B., Sørensen, S., Barnes, I., Becker, K. H., Etzkorn, T., Volkamer, R., Platt, U., Wirtz, K., and Martín-Reviejo, M.: Atmospheric Oxidation of Toluene in a Large-Volume Outdoor Photoreactor: In Situ Determination of Ring-Retaining Product Yields, J. Phys. Chem. A, 102, 10289-10299, https://doi.org/10.1021/jp982719n, 1998.

Krechmer, J. E., Pagonis, D., Ziemann, P. J., and Jimenez, J. L.: Quantification of Gas-Wall Partitioning in Teflon Environmental Chambers Using Rapid Bursts of Low-Volatility Oxidized Species Generated in Situ, Environ. Sci. Technol., 50, 57575765, https://doi.org/10.1021/acs.est.6b00606, 2016.

Kroll, J. H. and Seinfeld, J. H.: Chemistry of secondary organic aerosol: Formation and evolution of low-volatility organics in the atmosphere, Atmos. Environ., 42, 3593-3624, https://doi.org/10.1016/j.atmosenv.2008.01.003, 2008.

Krumins, V., Son, E.-K., Mainelis, G., and Fennell, D. E.: Retention of Inactivated Bioaerosols and Ethene in a Rotating Bioreactor Constructed for Bioaerosol Activity Studies, CLEAN - Soil, Air, Water, 36, 593-600, https://doi.org/10.1002/clen.200800004, 2008 .
Kulmala, M. and Kerminen, V.-M.: On the formation and growth of atmospheric nanoparticles, Atmos. Res., 90, 132-150, https://doi.org/10.1016/j.atmosres.2008.01.005, 2008.

Kulmala, M., Vehkamäki, H., Petäjä, T., Dal Maso, M., Lauri, A., Kerminen, V. M., Birmili, W., and McMurry, P. H.: Formation and growth rates of ultrafine atmospheric particles: A review of observations, J. Aerosol Sci., 35, 143-176, https://doi.org/10.1016/j.jaerosci.2003.10.003, 2004.

Laj, P., Klausen, J., Bilde, M., Plaß-Duelmer, C., Pappalardo, G., Clerbaux, C., Baltensperger, U., Hjorth, J., Simpson, D., Reimann, S., Coheur, P.-F., Richter, A., De Mazière, M., Rudich, Y., McFiggans, G., Torseth, K., Wiedensohler, A., Morin, S., Schulz, M., Allan, J. D., Attié, J.-L., Barnes, I., Birmili, W., Cammas, J. P., Dommen, J., Dorn, H.-P., Fowler, D., Fuzzi, S., Glasius, M., Granier, C., Hermann, M., Isaksen, I. S. A., Kinne, S., Koren, I., Madonna, F., Maione, M., Massling, A., Moehler, O., Mona, L., Monks, P. S., Müller, D., Müller, T., Orphal, J., Peuch, V.-H., Stratmann, F., Tanré, D., Tyndall, G., Abo Riziq, A., Van Roozendael, M., Villani, P., Wehner, B., Wex, H., and Zardini, A. A.: Measuring atmospheric composition change, Atmos. Environ., 43, 5351-5414, https://doi.org/10.1016/j.atmosenv.2009.08.020, 2009.

Lee, S., Jang, M., and Kamens, R. M.: SOA formation from the photooxidation of $\alpha$-pinene in the presence of freshly emitted diesel soot exhaust, Atmos. Environ., 38, 2597-2605, https://doi.org/10.1016/j.atmosenv.2003.12.041, 2004.

Lee, S. B., Bae, G. N., and Moon, K. C.: Smog Chamber Measurements, in: Atmospheric and Biological Environmental Monitoring, edited by: Kim, Y. J., Platt, U., Gu, M. B., and Iwahasi, H., Springer, Dordrecht, 105-136, https://doi.org/10.1007/9781-4020-9674-7_8, 2009.

Leong, Y. J., Sanchez, N. P., Wallace, H. W., Karakurt Cevik, B., Hernandez, C. S., Han, Y., Flynn, J. H., Massoli, P., Floerchinger, C., Fortner, E. C., Herndon, S., Bean, J. K., Hildebrandt Ruiz, L., Jeon, W., Choi, Y., Lefer, B., and Griffin, R. J.: Overview of surface measurements and spatial characterization of submicrometer particulate matter during the DISCOVER-AQ 2013 campaign in Houston, TX, J. Air Waste Manage. Assoc., 67, 854-872, https://doi.org/10.1080/10962247.2017.1296502, 2017.

Martin-Reviejo, M. and Wirtz, K.: Is Benzene a Precursor fo Secondary Organic Aerosol?, Environ. Sci. Technol., 39, 10451054, https://doi.org/10.1021/es049802a, 2005.

Massabò, D., Danelli, S. G., Brotto, P., Comite, A., Costa, C., Di Cesare, A., Doussin, J. F., Ferraro, F., Formenti, P., Gatta, E., Negretti, L., Oliva, M., Parodi, F., Vezzulli, L., and Prati, P.: ChAMBRe: a new atmospheric simulation chamber for aerosol modelling and bio-aerosol research, Atmos. Meas. Tech., 11, 58855900, https://doi.org/10.5194/amt-11-5885-2018, 2018.

Matsunaga, A. and Ziemann, P. J.: Gas-wall partitioning of organic compounds in a teflon film chamber and potential effects on reaction product and aerosol yield measurements, Aerosol Sci. Technol., 44, 881-892, https://doi.org/10.1080/02786826.2010.501044, 2010.

Paulsen, D., Dommen, J., Kalberer, M., Prévôt, A. S. H., Richter, R., Sax, M., Steinbacher, M., Weingartner, E., and Baltensperger, U.: Secondary Organic Aerosol Formation by Irradiation of 1,3,5Trimethylbenzene- $\mathrm{NO}_{x}-\mathrm{H}_{2} \mathrm{O}$ in a New Reaction Chamber for Atmospheric Chemistry and Physics, Environ. Sci. Technol., 39, 2668-2678, https://doi.org/10.1021/es0489137, 2005. 
Peng, J., Hu, M., Guo, S., Du, Z., Zheng, J., Shang, D., Levy Zamora, M., Zeng, L., Shao, M., Wu, Y.-S., Zheng, J., Wang, Y., Glen, C. R., Collins, D. R., Molina, M. J., and Zhang, R.: Markedly enhanced absorption and direct radiative forcing of black carbon under polluted urban environments, P. Natl. Acad. Sci., 113, 4266-4271, https://doi.org/10.1073/pnas.1602310113, 2016.

Peng, J., Hu, M., Guo, S., Du, Z., Shang, D., Zheng, J., Zheng, J., Zeng, L., Shao, M., Wu, Y., Collins, D., and Zhang, R.: Ageing and hygroscopicity variation of black carbon particles in Beijing measured by a quasi-atmospheric aerosol evolution study (QUALITY) chamber, Atmos. Chem. Phys., 17, 10333-10348, https://doi.org/10.5194/acp-17-10333-2017, 2017.

Platt, S. M., El Haddad, I., Zardini, A. A., Clairotte, M., Astorga, C., Wolf, R., Slowik, J. G., Temime-Roussel, B., Marchand, N., Ježek, I., Drinovec, L., Močnik, G., Möhler, O., Richter, R., Barmet, P., Bianchi, F., Baltensperger, U., and Prévôt, A. S. H.: Secondary organic aerosol formation from gasoline vehicle emissions in a new mobile environmental reaction chamber, Atmos. Chem. Phys., 13, 9141-9158, https://doi.org/10.5194/acp13-9141-2013, 2013.

Presto, A. A., Huff Hartz, K. E., and Donahue, N. M.: Secondary Organic Aerosol Production from Terpene Ozonolysis. 1. Effect of UV Radiation, Environ. Sci. Technol., 39, 7036-7045, https://doi.org/10.1021/es050174m, 2005.

Ren, Y., Grosselin, B., Daële, V., and Mellouki, A.: Investigation of the reaction of ozone with isoprene, methacrolein and methyl vinyl ketone using the HELIOS chamber, Faraday Discuss., 200, 289-311, https://doi.org/10.1039/C7FD00014F, 2017.

Rohrer, F., Bohn, B., Brauers, T., Brüning, D., Johnen, F.-J., Wahner, A., and Kleffmann, J.: Characterisation of the photolytic HONO-source in the atmosphere simulation chamber SAPHIR, Atmos. Chem. Phys., 5, 2189-2201, https://doi.org/10.5194/acp5-2189-2005, 2005.

Rollins, A. W., Kiendler-Scharr, A., Fry, J. L., Brauers, T., Brown, S. S., Dorn, H.-P., Dubé, W. P., Fuchs, H., Mensah, A., Mentel, T. F., Rohrer, F., Tillmann, R., Wegener, R., Wooldridge, P. J., and Cohen, R. C.: Isoprene oxidation by nitrate radical: alkyl nitrate and secondary organic aerosol yields, Atmos. Chem. Phys., 9, 6685-6703, https://doi.org/10.5194/acp-9-6685-2009, 2009.

Saathoff, H., Moehler, O., Schurath, U., Kamm, S., Dippel, B., and Mihelcic, D.: The AIDA soot aerosol characterisation campaign 1999, J. Aerosol Sci., 34, 1277-1296, https://doi.org/10.1016/S0021-8502(03)00363-X, 2003.

Santarpia, J. L., Ratnesar-Shumate, S., and Haddrell, A.: Laboratory study of bioaerosols: Traditional test systems, modern approaches, and environmental control, Aerosol Sci. Technol., 54, 585-600, https://doi.org/10.1080/02786826.2019.1696452, 2020.

Seakins, P. W.: A brief review of the use of environmental chambers for gas phase studies of kinetics, chemical mechanisms and characterisation of field instruments, EPJ Web Conf., 9, 143-163, https://doi.org/10.1051/epjconf/201009012, 2010.

Shibuya, K., Nagashima, T., Imai, S., and Akimoto, H.: Photochemical Ozone Formation in the Irradiation of Ambient Air Samples by Using a Mobile Smog Chamber, Environ. Sci. Technol., 15, 661-665, https://doi.org/10.1021/es00088a003, 1981.

Smith, D. M., Fiddler, M. N., Sexton, K. G., and Bililign, S.: Construction and Characterization of an Indoor Smog Chamber for
Measuring the Optical and Physicochemical Properties of Aging Biomass Burning Aerosols, Aerosol Air Qual. Res., 19, 467-483, https://doi.org/10.4209/aaqr.2018.06.0243, 2019.

Stolzenburg, M., Kreisberg, N., and Hering, S.: Atmospheric Size Distributions Measured by Differential Mobility Optical Particle Size Spectrometry, Aerosol Sci. Technol., 29, 402-418, https://doi.org/10.1080/02786829808965579, 1998.

Stolzenburg, M. R., McMurry, P. H., Sakurai, H., Smith, J. N., Mauldin, R. L., Eisele, F. L., and Clement, C. F.: Growth rates of freshly nucleated atmospheric particles in Atlanta, J. Geophys. Res., 110, D22S05, https://doi.org/10.1029/2005JD005935, 2005.

Sutton, T.: Decay of particle concentration as a function of rotation rate in a rotating drum chamber. No. ECBC-TR-436, Edgewood Chemical Biological Center Aberdeen Proving Ground MD, USA, 2005.

Tkacik, D. S., Robinson, E. S., Ahern, A., Saleh, R., Stockwell, C., Veres, P., Simpson, I. J., Meinardi, S., Blake, D. R., Yokelson, R. J., Presto, A. A., Sullivan, R. C., Donahue, N. M., and Robinson, A. L.: A dual-chamber method for quantifying the effects of atmospheric perturbations on secondary organic aerosol formation from biomass burning emissions, J. Geophys. Res.-Atmos., 122, 6043-6058, https://doi.org/10.1002/2016JD025784, 2017.

Tröstl, J., Chuang, W. K., Gordon, H., Heinritzi, M., Yan, C., Molteni, U., Ahlm, L., Frege, C., Bianchi, F., Wagner, R., Simon, M., Lehtipalo, K., Williamson, C., Craven, J. S., Duplissy, J., Adamov, A., Almeida, J., Bernhammer, A.-K., Breitenlechner, M., Brilke, S., Dias, A., Ehrhart, S., Flagan, R. C., Franchin, A., Fuchs, C., Guida, R., Gysel, M., Hansel, A., Hoyle, C. R., Jokinen, T., Junninen, H., Kangasluoma, J., Keskinen, H., Kim, J., Krapf, M., Kürten, A., Laaksonen, A., Lawler, M., Leiminger, M., Mathot, S., Möhler, O., Nieminen, T., Onnela, A., Petäjä, T., Piel, F. M., Miettinen, P., Rissanen, M. P., Rondo, L., Sarnela, N., Schobesberger, S., Sengupta, K., Sipilä, M., Smith, J. N., Steiner, G., Tomè, A., Virtanen, A., Wagner, A. C., Weingartner, E., Wimmer, D., Winkler, P. M., Ye, P., Carslaw, K. S., Curtius, J., Dommen, J., Kirkby, J., Kulmala, M., Riipinen, I., Worsnop, D. R., Donahue, N. M., and Baltensperger, U.: The role of low-volatility organic compounds in initial particle growth in the atmosphere, Nature, 533, 527-531, https://doi.org/10.1038/nature18271, 2016.

Vu, D., Roth, P., Berte, T., Yang, J., Cocker, D., Durbin, T. D., Karavalakis, G., and Asa-Awuku, A.: Using a new Mobile Atmospheric Chamber (MACh) to investigate the formation of secondary aerosols from mobile sources: The case of gasoline direct injection vehicles, J. Aerosol Sci., 133, 1-11, https://doi.org/10.1016/j.jaerosci.2019.03.009, 2019.

Wallace, H. W., Sanchez, N. P., Flynn, J. H., Erickson, M. H., Lefer, B. L., and Griffin, R. J.: Source apportionment of particulate matter and trace gases near a major refinery near the Houston Ship Channel, Atmos. Environ., 173, 16-29, https://doi.org/10.1016/j.atmosenv.2017.10.049, 2018.

Wang, J., Doussin, J. F., Perrier, S., Perraudin, E., Katrib, Y., Pangui, E., and Picquet-Varrault, B.: Design of a new multi-phase experimental simulation chamber for atmospheric photosmog, aerosol and cloud chemistry research, Atmos. Meas. Tech., 4, 2465-2494, https://doi.org/10.5194/amt-4-2465-2011, 2011.

Wang, X., Liu, T., Bernard, F., Ding, X., Wen, S., Zhang, Y., Zhang, Z., He, Q., Lü, S., Chen, J., Saunders, S., and Yu, 
J.: Design and characterization of a smog chamber for studying gas-phase chemical mechanisms and aerosol formation, Atmos. Meas. Tech., 7, 301-313, https://doi.org/10.5194/amt-7301-2014, 2014.

Weitkamp, E. A., Sage, A. M., Pierce, J. R., Donahue, N. M., and Robinson, A. L.: Organic Aerosol Formation from Photochemical Oxidation of Diesel Exhaust in a Smog Chamber, Environ. Sci. Technol., 41, 6969-6975, https://doi.org/10.1021/es070193r, 2007.
Yli-Juuti, T., Barsanti, K., Hildebrandt Ruiz, L., Kieloaho, A.J., Makkonen, U., Petäjä, T., Ruuskanen, T., Kulmala, M., and Riipinen, I.: Model for acid-base chemistry in nanoparticle growth (MABNAG), Atmos. Chem. Phys., 13, 12507-12524, https://doi.org/10.5194/acp-13-12507-2013, 2013.

Zhong, M. and Jang, M.: Dynamic light absorption of biomass-burning organic carbon photochemically aged under natural sunlight, Atmos. Chem. Phys., 14, 1517-1525, https://doi.org/10.5194/acp-14-1517-2014, 2014. 